\title{
LA FAMILIA APOCYNACEAE (APOCYNOIDEAE Y RAUVOLFIOIDEAE) EN EL ESTADO DE MORELOS, MÉXICO
}

\author{
Edith González-Rocha ${ }^{1}$ y Rosa Cerros-Tlatilpa ${ }^{1,2}$ \\ ${ }^{1}$ Universidad Autónoma del Estado de Morelos, Facultad de Ciencias Biológicas, \\ Laboratorio de Sistemática y Morfología, Avenida Universidad 1001, Colonia \\ Chamilpa, 62209 Cuernavaca, Morelos, México. \\ 2Autor para la correspondencia: tlatilpa@uaem.mx
}

\section{RESUMEN}

Se presenta el estudio de la familia Apocynaceae (Apocynoideae y Rauvolfioideae) en el estado de Morelos, México. Como resultado se encontraron diez géneros y 14 especies: Cascabela (2), Haplophyton (1), Laubertia (1), Mandevilla (3), Plumeria (1), Prestonia (1), Rauvolfia (1), Tabernaemontana (2), Thenardia (1) y Tonduzia (1). La subfamilia Rauvolfioideae es la mejor representada con seis géneros y ocho especies, mientras que Apocynoideae tiene cuatro y seis, respectivamente. La mayoría de los taxa crecen en el bosque tropical caducifolio, en el bosque de Quercus, en bosque de galería y en bosque de coníferas. En el estado se distribuyen seis de las 29 especies endémicas de México reportadas para estas subfamilias: Cascabela thevetioides, Laubertia contorta, Mandevilla foliosa, $M$. holosericea, Tabernaemontana tomentosa y Thenardia floribunda. Se incluyen claves de identificación, descripciones, nombres comunes, ejemplares examinados y recolectados, altitud registrada, mapas de distribución y fotografías.

Palabras clave: Apocynaceae, florística, estado de Morelos, taxonomía de plantas.

\section{ABSTRACT}

Results are presented for the study of Apocynaceae (Apocynoideae and Rauvolfioideae) in the state of Morelos, Mexico. We found ten genera and 14 species: Cascabela (2), Haplophyton (1), Laubertia (1), Mandevilla (3), Plumeria (1), Prestonia (1), Rauvolfia (1), Tabernaemontana (2), Thenardia (1) and Tonduzia (1). Subfamily Rauvolfioideae is well represented with six genera and eight species, whereas Apocynoideae 
has four and six, respectively. Most taxa grow in tropical deciduous forest, oak forest, gallery forest and coniferous forest. Six of the 29 endemic species of Mexico are present in Morelos: Cascabela thevetioides, Laubertia contorta, Mandevilla foliosa, M. holosericea, Tabernaemontana tomentosa y Thenardia floribunda. This study includes identification keys, descriptions, common names, specimen examined and recollected, elevation recorded, distribution maps and photographs.

Key words: Apocynaceae, floristic, plant taxonomy, State of Morelos.

\section{INTRODUCCIÓN}

Apocynaceae es una familia de angiospermas de distribución mayormente tropical y subtropical, aunque algunas especies se encuentran en regiones templadas; comprende cinco subfamilias, 375 géneros y ca. 5000 especies (Endress, 2004; Endress et al., 2007). Para México se reportan tres subfamilias, la mejor representada es Asclepiadoideae con 22 géneros y 288 especies, seguida por Apocynoideae con 15 géneros y 56 especies y por último Rauvolfioideae con 13 géneros y 41 especies, y es considerada una de las 15 familias más diversas de México (Juárez-Jaimes et al., 2007). Para el estado de Morelos se registran 24 géneros y 68 especies de Apocynaceae (Juárez-Jaimes et al., 2007).

La familia está bien representada en casi todo el país, pero la mayor diversidad se concentra en la parte centro y sur de México (Juárez-Jaimes et al., 2007). Las especies habitan en el bosque tropical caducifolio, el bosque tropical subcaducifolio, en matorrales xerófilos, en el bosque de coníferas y el bosque de Quercus (Fagaceae) (Alvarado-Cárdenas, 2003, 2004a, 2004b; Juárez-Jaimes et al., 2007). Por otra parte, las apocináceas en México tienen importancia farmacéutica, ornamental y ceremonial (Chimal y Corona, 2003; Alvarado-Cárdenas, 2004a; JuárezJaimes et al., 2007).

Para Morelos se han realizado diversos trabajos florísticos que han incluido a las apocináceas, algunos de ellos abarcando ciertas regiones (Soria, 1985; Cerros-Tlatilpa y Espejo-Serna, 1998), otros contemplando algunos municipios (Flores, 1988; Galindo y Fernández, 2002), reservas naturales (Dorado et al., 2005; Flores-Castorena y Martínez-Alvarado, 2010) y listados para el estado (Vázquez, 1974; Bonilla-Barbosa y Villaseñor, 2003). En 2007, Juárez-Jaimes et al. proporcionaron una lista de especies de Apocynaceae presentes en el país, donde se reconocen 21 especies para la entidad. Sin embargo, no hay un trata- 
miento taxonómico de esta familia en el estado. En esta contribución se presenta el estudio de las subfamilias Apocynoideae y Rauvolfioideae (Endress y Bruyns, 2000).

Área de estudio

Morelos se encuentra situado en la parte sur de la región central de la República Mexicana, entre los $19^{\circ} 08^{\prime}$ y $18^{\circ} 20^{\prime} \mathrm{N}$ y $98^{\circ} 38^{\prime}$ y $99^{\circ} 30^{\prime} \mathrm{W}$ (Fig. 1). Es una de las entidades federativas más pequeñas de México con $4958 \mathrm{~km}^{2}$, cifra que representa $0.2 \%$ de la superficie del país (Anónimo, 1999). Fisiográficamente se encuentra entre dos provincias: 1) el eje Volcánico Transversal en su parte alta al norte y 2) la depresión del Balsas en su región más baja al centro sur del estado, alcanzando una altitud mínima de 720 m en el río Amacuzac y una máxima en la Sierra Nevada del Popocatépetl con 5465 m (Anónimo, 2000).

Morelos se localiza, casi en su totalidad, en la región hidrológica del Río Balsas y forma parte de dos cuencas: 1) la del Río Amacuzac, con 12 afluentes que ocupan 1650 ha (entre ellos los ríos Bajo Amacuzac, Cuautla, Yautepec, Apatlaco, Tembembe y río Alto Amacuzac) y 2) la Cuenca del Río Atoyac, teniendo este último su mayor extensión en Puebla (Anónimo, 1981).

El clima predominante en $72 \%$ de la superficie estatal es el cálido subhúmedo, que se encuentra en la zona centro y sur; seguido por el semicálido subhúmedo, en una franja en la región norte, que va desde este a oeste, abarcando cerca de $16 \%$ de la superficie estatal. La zona norte de la entidad es de tipo templado subhúmedo y caracteriza a localidades como Huitzilac, Tres Cumbres, Coajomulco, Tlacualera y Apapasco; mientras que $2.2 \%$ del estado es frío y semifrío, reduciéndose a pequeñas áreas localizadas en el Popocatépetl y al noreste en los límites con el Estado de México y el Distrito Federal (Contreras-MacBeath et al., 2004).

Dentro de los límites de Morelos se desarrollan ocho tipos de vegetación sensu Rzedowski (1978): bosque de coníferas, bosque de Quercus, bosque mesófilo de montaña, bosque tropical caducifolio, bosque de galería, matorral xerófilo, pastizal y vegetación acuática. En el norte del estado se ubican los bosques de coníferas más densos y altos donde dominan en la totalidad de las partes altas del eje Volcánico Transversal, con 10,335 ha. El bosque de Quercus se encuentra en altitudes entre los 1500 y 2200 m, ocupando una superficie aproximada de 10832 ha. El bosque mesófilo de montaña localizado en los municipios de Huitzilac, Tepoztlán y Tlayacapan cubre una pequeña porción en las laderas de las barrancas húmedas (ContrerasMacBeath et al., 2004; Hernández-Cárdenas, 2012). El bosque tropical caducifolio cubre la mayor extensión superficial del estado, con aproximadamente 56000 ha, se 


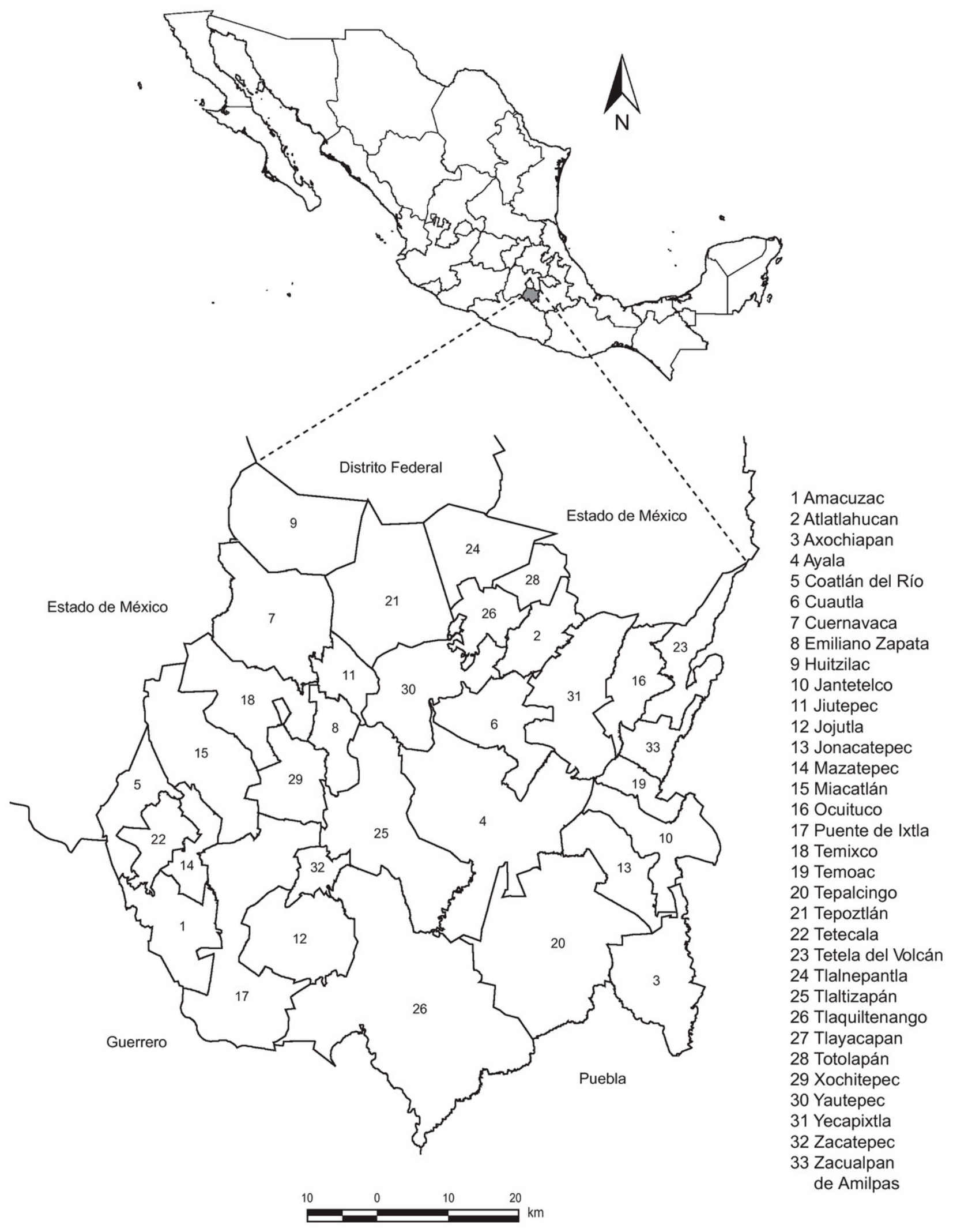

Fig. 1. Localización geográfica y división política del estado de Morelos en México (Proporcionado por el Laboratorio Interdisciplinario de Sistemas de Información Geográfica (LISIG), Universidad Autónoma del Estado de Morelos (Anónimo, 2012). 
distribuye entre los 800 y los 1800 m s.n.m. (Anónimo, 1994; Dorado et al., 2005). El bosque de galería comprende a las agrupaciones que se desarrollan a lo largo de corrientes de agua, este tipo de vegetación es a menudo asociado al bosque tropical caducifolio, entre los 800 y $1800 \mathrm{~m}$ de altitud. El matorral xerófilo se ubica en la parte centro-norte del corredor biológico Chichinautzin (Anónimo, 1988). Finalmente los pastizales en el estado de Morelos son secundarios o inducidos y se localizan en la región oriente como en Axochiapan, Ayala, Jantetelco, Tepalcingo y Yecapixtla y en la región poniente como en Amacuzac, Coatlán del Río, Puente de Ixtla y Miacatlán.

\section{MATERIALES Y MÉTODOS}

Se llevó a cabo una revisión de material herborizado de la familia Apocynaceae (subfamilias Apocynoideae y Rauvolfioideae) para el estado de Morelos depositados en los herbarios ENCB, FCME, HUMO, MEXU, UAMIZ (acrónimos del Index Herbariorum [IH]) y MORE (no registrado en el IH). Además, se recolectaron ejemplares botánicos en los diversos municipios del estado y se obtuvo información de la altitud, geoposición, tipos de vegetación en donde se localizan, así como de características del ejemplar que pudieran perderse con el secado. Dicho material fue depositado en los herbarios HUMO y UAMIZ y se enviaron duplicados a IEB y MEXU. Para la determinación de especies se utilizaron las claves taxonómicas y las descripciones de los trabajos de Standley, 1924; Standley y Williams, 1966; Woodson, 1933, 1936a, 1936b, 1938a, 1938b; Rao, 1956; Williams, 1995, 1996, 1998b; Morales, 1995, 1996, 1997, 1998, 2002, 2009; Morales y Méndez, 2005; AlvaradoCárdenas, 2007 y Alvarado-Cárdenas y Ochoterena, 2007. Se elaboraron mapas de distribución geográfica de las especies y se incluyeron fotografías de las mismas.

\section{APOCYNACEAE JUSS.}

Árboles, arbustos, hierbas erectas o escandentes y lianas, con látex blanco, transparente, amarillo, de color crema a rojizo o anaranjado; tallos cilíndricos, aplanados o angulados, algunas veces suberosos, con o sin coléteres intra e interpeciolares, algunas veces muy desarrollados pareciendo garras en Mandevilla. Hojas simples, opuestas, subopuestas, alternas o verticiladas, algunas veces dispuestas en espiral, pecioladas o sésiles, estípulas raramente presentes, algunas veces con coléteres en la vena media, ya sea agrupados en su base o distribuidas a lo largo 
del nervio central, o bien, dispuestos a lo largo del peciolo, las láminas glabras o pubescentes, con el margen entero, con venación generalmente broquidódroma, a veces eucamptódroma. Inflorescencias cimosas, racemosas o bien las flores solitarias, axilares o terminales; por lo común los pedicelos o pedúnculos provistos de brácteas y bracteolas florales, foliáceas o escariosas, generalmente deciduas en la fructificación. Flores perfectas, actinomorfas, simpétalas, 5-meras, sépalos iguales o desiguales, evidentes o inconspicuos, imbricados, con o sin coléteres en la base de la cara adaxial; corola hipocrateriforme, infundibuliforme, rotada, tubular o urceolada, amarilla, blanca, rosada, roja o azul, a veces con estructuras coronales accesorias (coronas anulares y lóbulos coronales libres, éstos a veces reducidos a crestas callosas), limbo con 5 lóbulos, sinistrocontortos o dextrocontortos; estambres 5 incluidos o exertos, filamentos generalmente cortos, a veces largos (e.g. Thenardia), anteras basifijas, biloculares, por lo común introrsas, pero a veces extrorsas, conniventes y aglutinadas a la cabeza estigmática o libres, provistas a veces de apéndices supraestaminales; gineceo bicarpelar, con ovario apocárpico o sincárpico (e.g. Allamanda y Carissa), ovario súpero, raramente semiínfero (Plumeria), estilo simple; la parte superior del gineceo forma una estructura especializada, denominada estigma, cabeza estilar o cabeza estigmática (Juárez-Jaimes et al., 2007), ovario rodeado de nectarios o éstos ausentes. Frutos apocárpicos o sincárpicos, folículos, cápsulas, drupas o bayas; semillas a veces aladas, a menudo comosas en el ápice micropilar o calazal, o en ambos lados, desnudas o cubiertas por un arilo.

Clave para la determinación de géneros de Apocynaceae (Apocynoideae y Rauvolfioideae)

1 Prefloración dextrocontorta de los lóbulos de la corola

2 Hojas con coléteres en la lámina, distribuidos a lo largo de la vena media o agrupados en la base de la cara adaxial

Mandevilla

2 Hojas sin coléteres en la lámina

3 Lianas; inflorescencias cimosas, semillas comosas en el ápice micropilar

4 Corola rotada, sin coronas anulares; gineceo sincárpico Thenardia

4 Corola hipocrateriforme, con coronas anulares; gineceo apocárpico

5 Sépalos con un coléter en la base de la cara adaxial; corola amarilla; folículos divaricados, hirsutos Prestonia

5 Sépalos sin coléteres en la base de la cara adaxial; corola de color violeta o vino; folículos no divaricados, glabros a puberulentos 
3 Plantas herbáceas sufrutescentes; flores solitarias, semillas comosas en el ápice micropilar y calazal Haplophyton

1 Prefloración sinistrocontorta de los lóbulos de la corola

6 Hojas opuestas; folículos subglobosos; semillas no comosas, rodeadas por un arilo rojo o anaranjado Tabernaemontana

6 Hojas alternas o verticiladas; drupas o folículos teretes; semillas comosas, aladas o ciliadas

7 Hojas alternas

8 Inflorescencia un corimbo; corola hipocrateriforme, blanca o rosada con la garganta amarilla; fruto un folículo; semillas aladas Plumeria

8 Inflorescencia una cima; corola infundibuliforme, amarilla o anaranjada; fruto una drupa; semillas no aladas Cascabela

7 Hojas en verticilos

9 Fruto un folículo; semillas ciliadas en el margen; corola hipocrateriforme; cabeza estigmática fusiforme Tonduzia

9 Fruto una drupa; semillas no ciliadas en el margen; corola urceolada; cabeza estigmática más o menos cilíndrica Rauvolfia

CASCABELA Raf., Sylva Tellur.1 62. 1838.

Árboles o arbustos, raramente hierbas; tallos subcilíndricos, con látex blanco, glabros a puberulentos, con coléteres intrapeciolares diminutos e inconspicuos. Hojas alternas, dispuestas en espiral, pecioladas o sésiles, sin coléteres en la lámina, las láminas glabras a puberulentas, membranáceas o coriáceas. Inflorescencia una cima axilar, subterminal o terminal; brácteas florales escariosas; cáliz con sépalos iguales, foliáceos, pubescentes, con numerosos coléteres dispuestos en la base de la cara adaxial; corola infundibuliforme, amarilla o anaranjada, sin corona anular, el interior del tubo con 5 lóbulos coronales opuestos sobre cada antera, pubescentes, prefloración sinistrocontorta, tubo floral sin crestas supra e infraestaminales, recto; estambres incluidos, anteras conniventes y aglutinadas a la cabeza estigmática, con apéndices supra e infraestaminales; cabeza estigmática cónica, lobulada en la base; gineceo apocárpico, bicarpelar, ovario súpero, con un nectario anular, a veces 5-lobado. Fruto una drupa, sincárpico, obpiramidal-subgloboso a subgloboso, con el exocarpo carnoso, verde cuando joven, morado al madurar, el mesocarpo carnoso, el endocarpo pétreo; semillas glabras, no comosas.

Género con cinco especies distribuidas en México y Centroamérica, una ampliamente cultivada en los trópicos; cinco especies presentes en México, dos en 
Morelos. En este trabajo se sigue la propuesta de Alvarado-Cárdenas y Ochoterena (2007), en la cual se reconoce el género Cascabela caracterizado por la presencia de apéndices supraestaminales digitiformes, separado de Thevetia que los tiene deltoides.

Clave para la determinación de las especies de Cascabela

1 Hojas elípticas, oblanceoladas u oblongas, con marcada venación secundaria en ambas superficies; peciolos de 6-8 mm de largo; lámina foliar con el ápice ligeramente obtuso o redondeado C. ovata

1 Hojas lanceoladas o lineares, sin marcada venación secundaria en ambas superficies; peciolos de 28-40 mm de largo; lámina foliar con el ápice acuminado C. thevetioides

Cascabela ovata (Cav.) Lippold, Feddes Repert. 91(1-2): 53. 1980. Cerbera ovata Cav., Icon. 3: 35-36, t. 270. 1796. Thevetia ovata (Cav.) A. DC., Prodr. 8: 344. 1844. Tipo: México. Nueva España, sin datos (Holotipo: MA). Fig. 2A.

Nombres comunes registrados en la zona: ayoyote, yoyote (Lorenzana 3, UAMIZ; Martínez, 1991).

Árboles o arbustos de 3-6 m de altura; tallos subcilíndricos, puberulentos, coléteres intrapeciolares de ca. $1.5 \mathrm{~mm}$ de largo. Hojas alternas, dispuestas en espiral, láminas elípticas, oblanceoladas u oblongas, de 5-14 cm de largo $\times 2.5-7.5 \mathrm{~cm}$ de ancho, ápice ligeramente obtuso o redondeado, base cuneada, haz pubescente, envés tomentuloso, con marcada venación secundaria en ambas superficies, subcoriáceas, peciolos de 6-8 $\mathrm{mm}$ de largo, generalmente puberulentos, rara vez glabros. Inflorescencia una cima terminal de 3-6 flores, pedúnculo de $1.2-6 \mathrm{~cm}$ de largo $\times$ 1-2 mm de diámetro, indumento glabro a puberulento, pedicelo de $1.4-5 \mathrm{~cm}$ de largo, piloso; brácteas florales verdes, ovadas, de 5-7.2 $\mathrm{mm}$ de largo $\times 1.9-5 \mathrm{~mm}$ de ancho, pubescentes; cáliz con 5 sépalos verdes, ovados, de 5.6-11.5 mm de largo $\times 2$-4.3 $\mathrm{mm}$ de ancho, pubescentes, con 16 a 18 coléteres; corola infundibuliforme, amarilla, porción inferior del tubo de 1-2.5 cm de largo, porción superior campanulada, de 1.2$2.3 \mathrm{~cm}$ de largo, diámetro de la garganta de $2.3-2.5 \mathrm{~cm}$, lóbulos oblongo-obovados, 2.4-4 cm de largo $\times 2.3-2.5 \mathrm{~cm}$ de ancho, extendidos; estambres incluidos, filamentos de ca. $1 \mathrm{~mm}$ de largo, anteras de ca. $2 \mathrm{~mm}$ de largo, aglutinadas a la cabeza estigmática; ésta de ca. $2 \mathrm{~mm}$ de largo, estilo de 1.4-1.5 cm de largo; ovario de ca. 2 
$\mathrm{mm}$ de largo, nectario de ca. $2 \mathrm{~mm}$ de largo. Drupas verdes, moradas en la madurez, obpiramidal-subglobosas, con lenticelas blanquecinas, de 2-3.3 $\mathrm{cm}$ de largo $\times 3-5$ $\mathrm{cm}$ de diámetro, glabras; semillas de 1.7-2.1 $\mathrm{cm}$ de largo $\times 1.8 \mathrm{~cm}$ de ancho.

Se distribuye en Costa Rica, El Salvador, Guatemala, Honduras, México y Nicaragua (Alvarado-Cárdenas y Ochoterena, 2007). En el país se conoce de Chiapas, Colima, Durango, Guerrero, Jalisco, México, Michoacán, Morelos, Nayarit, Oaxaca, Puebla, Sinaloa y Zacatecas (Juárez-Jaimes et al., 2007). En Morelos se ha encontrado en los municipios de Amacuzac, Coatlán del Río, Cuernavaca, Jojutla, Miacatlán, Puente de Ixtla, Temixco, Tepalcingo, Tetecala, Tlaltizapan, Tlaquiltenango, Xochitepec y Yautepec. Fig. 3.

Especie abundante en el sur del estado en el bosque tropical caducifolio, en bosque de galería y en algunas zonas perturbadas con vegetación secundaria, en altitudes de 850 a $1870 \mathrm{~m}$. Florece entre mayo y agosto; fructifica entre julio y diciembre. Es de uso ornamental y en algunas zonas de Morelos el endocarpo es utilizado en danzas folklóricas como cascabeles. Planta que se diferencia de $C$. thevetioides por tener la lámina oblanceolada y por la marcada venación secundaria.

Ejemplares examinados: Amacuzac. Camino a Palo Grande, 18 ${ }^{\circ} 31^{\prime} 36.8^{\prime \prime}$ N, 99²1'27.3" W, Betancourt 47 (HUMO); Al SE de Zoquital, 18³1'11.8" N, 99²1'26.6" W, Betancourt 53 (HUMO). Coatlán del Río. Camino hacia El Hoyanco, 1844'11.1" N, 99²6'6.8" W, González-Rocha et al. 56 (UAMIZ); sin localidad, Torres 429 (FCME, MEXU). Cuernavaca. Tetela del Monte (barrancas), Lyonnet 17 (MEXU). Jojutla. Cerro Grande, más o menos 3 km al E de Jojutla, 15 abr 1955, Becerra s.n. (MEXU), Rzedowski 8888 (ENCB); cerro El Higuerón, cerca 2 km al S del centro del mpio., S del cerro, cuesta E, 18³5'20" N, 99 $09^{\prime} 10^{\prime \prime} \mathrm{W}$, Lauren 127 (HUMO); cerro El Higuerón, ladera NE, Rivera 159 (UAMIZ); cerro, ladera N, Vázquez 418 (MEXU). Miacatlán. Intersección a la zona arqueológica y Mazatepec, avenida 5 de Mayo, 1843'51.1" N, 99¹9'42.3" W, González-Rocha et al. 55 (UAMIZ); carretera a las Grutas de Cacahuamilpa, cerca de la desviación a Xochicalco, Vázquez 1768 (MEXU). Puente de Ixtla. 8 km al S de Chisco, 18³0'31" N, 99¹3'3.5" W, Castro 1257 (HUMO). Temixco. Santa Cruz, 16 feb 1955, Becerra s.n. (MEXU). Tepalcingo. Cerro del Jumil, antes desviación colonia Benito Juárez, 7 km antes de Michiapa, 18³5'59" N, 9851'19" W, Germán 463 (ENCB, MEXU). Tetecala. Tetecala, 1 ene 1954, Rudorli s.n. (ENCB); Llanos de Guarín - barranca del Terrón (entre la carretera y la barranca), Vázquez 2611 (MEXU). Tlaltizapan. Cuajiotal, cerca de Las Estacas, Rita 286 (FCME). Tlaquiltenango. $2.5 \mathrm{~km}$ al S de Coaxitlán, 18²5'19" N, 99¹1'01.9" W, Betancourt 78 (HUMO); $3.5 \mathrm{~km}$ al SE de Coaxitlán, 18²5'11" N, 9909'57.2" W, Betancourt 144 (HUMO); 600 m al NW de 

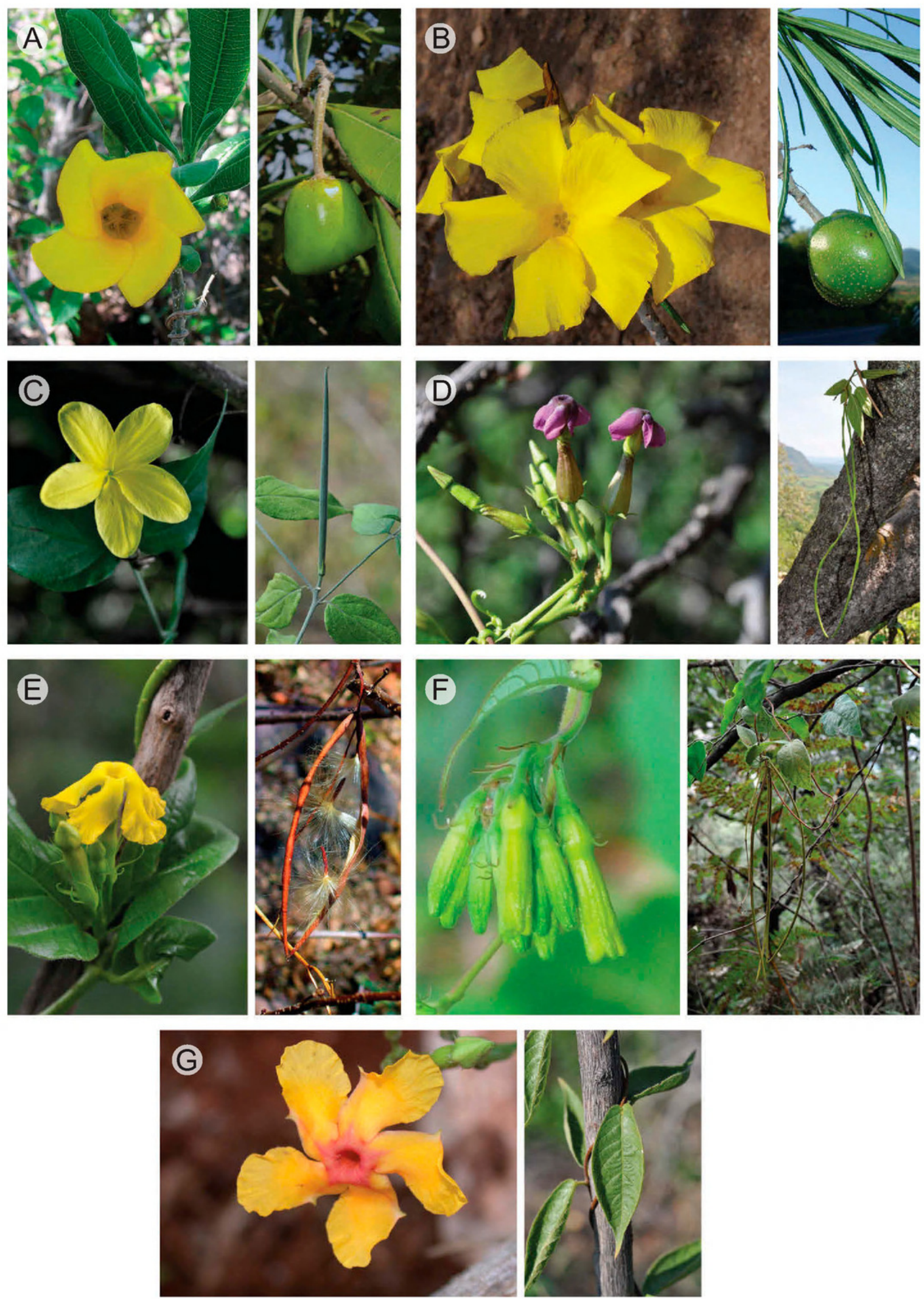

Fig. 2. Flores y frutos de Cascabela, Haplophyton, Laubertia y Mandevilla. A. Cascabela ovata; B. C. thevetioides; C. Haplophyton cimicidum; D. Laubertia contorta; E. Mandevilla foliosa; F. M. holosericea; G. M. subsagittata. 
Xicatlacota, $18^{\circ} 31^{\prime} 10.1^{\prime \prime}$ N, 99¹1'44.3" W, Betancourt 172 (HUMO); $1000 \mathrm{~m}$ al SE de Pueblo Viejo, 18³0'23.8" N, 99¹0'55.5" W, Betancourt 174 (HUMO); Valle de Vázquez (cerca de la carretera), Brito 01 (MEXU), Vázquez 2456 (MEXU); Barranquilla de los Coyotes, a $100 \mathrm{~m}$ de la carretera al oriente de CEAMISH, $18^{\circ} 27^{\prime} 4^{\prime \prime} \mathrm{N}, 9^{\circ} 0^{\prime} 57^{\prime \prime}$

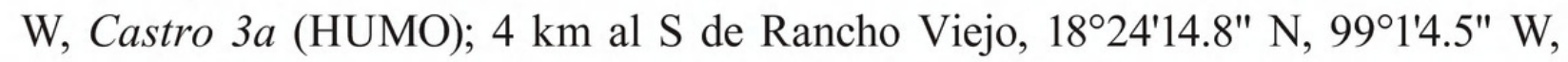
Castro 956 (HUMO); $2 \mathrm{~km}$ al S de Pueblo Viejo, 18³0'22" N, 99¹0'54" W, Cerros 807 (HUMO); camino que va al Perillo, a $1.25 \mathrm{~km}$ al W de Huaxtla, $18^{\circ} 22^{\prime 2} 25^{\prime \prime} \mathrm{N}$, 99 03'04" W, González-Rocha et al. 15 (UAMIZ); carretera a $2 \mathrm{~km}$ al SE de San Pablo Hidalgo, 18³3'54.8" N, 9902'09.6" W, González-Rocha et al. 23 (UAMIZ); Nexpa, a $10 \mathrm{~km}$ del Higuerón - Jojutla, Lorenzana 3 (UAMIZ); brecha Xicatlán a Xicatlacotla, 4 km al N de Xicatlán, Quezada 1699 (HUMO, MEXU, UAMIZ); 4 km al NW de Ajuchitlán, 18²4'37" N, 994'30" W, Ramírez 569 (HUMO); 2.25 km al NW de Huaxtla, 18²2'36" N, 99³'26" W, Ramírez 1622a (HUMO); 2 km al NE de Huautla, 18²6'29" N, 99²'24" W, Valdez 298 (HUMO, MEXU); $0.75 \mathrm{~km}$ al SE de Rancho Viejo, 18²5'3" N, 990'33" W, Valdez 326 (HUMO); 3.75 km al NW de Ajuchitlán, 18²7'55" N, 9859'1" W, Valdez 558 (HUMO). Xochitepec. km 6 carretera Alpuyeca - Grutas de Cacahuamilpa, El Cabrito, 20 may 1965, Palacios s.n. (ENCB). Yautepec. Barranca Honda, Camacho 67 (ENCB); 1 km al SW de barranca Honda, Espejo y Flores 2532 (UAMIZ).

Cascabela thevetioides (Kunth) Lippold, Feddes Repert. 91(1-2): 53. 1980. Cerbera thevetioides Kunth, Nov. Gen. Sp. (quarto ed.) 3: 223. 1818 [1819]. Thevetia thevetioides (Kunth) K. Schum., Die Nat. Pflanzenfam 4(2): 159. 1895. Tipo: México, Guerrero, Tasco et Tehuilotepec, Humboldt \& Bonpland 3971 (Holotipo: P-HB, foto MEXU). Fig. 2B.

Nombres comunes registrados en la zona: ayoyote, fraile, yoyote.

Árboles o arbustos de 3-7 m de altura; tallos subcilíndricos, pubescentes, coléteres intrapeciolares de ca. $1 \mathrm{~mm}$ de largo. Hojas alternas, dispuestas en espiral, láminas lanceoladas o lineares, de 9-17 cm de largo × 3-10 mm de ancho, ápice acuminado, base cuneada, haz generalmente glabro, envés piloso a lo largo de la vena media, sin marcada venación secundaria en ambas superficies, membranáceas, peciolos de $28-40 \mathrm{~mm}$ de largo, pubescentes. Inflorescencia una cima terminal de 3 a 12 flores, pedúnculo de $0.6-1.5 \mathrm{~cm}$ de largo, pubescente, pedicelo de $0.6-1.2 \mathrm{~cm}$ de largo, pubescente; brácteas florales verdes, lanceoladas a ovadas, de 3-4 mm de largo $\times 1 \mathrm{~mm}$ de ancho, puberulentas a glabras; cáliz con 5 sépalos verdes, oblongos 
u ovado-lanceolados, de 7-12 $\mathrm{mm}$ de largo $\times$ 1.5-3 $\mathrm{mm}$ de ancho, puberulentos o glabros, con hasta 25 coléteres; corola infundibuliforme, amarilla brillante, porción inferior del tubo de 0.9-1.6 cm de largo $\times 3-3.3 \mathrm{~mm}$ de diámetro, porción superior cónica o campanulada, de 1-1.2 cm de largo, diámetro de la garganta de $1.5-2 \mathrm{~cm}$, lóbulos oblicuamente obovados, de 4-5 $\mathrm{cm}$ de largo $\times 3-3.5 \mathrm{~cm}$ de ancho, extendidos; estambres incluidos, filamentos de $8-9 \mathrm{~mm}$ de largo, anteras de ca. $3 \mathrm{~mm}$ de largo; cabeza estigmática de 2-2.5 mm de largo, estilo de 1.8-2 cm de largo; ovario de 3-4 $\mathrm{mm}$ de largo, nectarios de ca. $1 \mathrm{~mm}$ de largo. Drupas verdes, moradas en la madurez, subglobosas, con lenticelas blanquecinas a pardas claras, de $2.4-4 \mathrm{~cm}$ de largo $\times$ 4-5.5 cm de diámetro, glabras; semillas de 1.4-1.6 cm de largo $\times 1.5-1.9 \mathrm{~cm}$ de ancho.

Especie endémica del centro y sur de México, conocida de Guanajuato, Guerrero, México, Michoacán, Morelos, Oaxaca, Puebla, Querétaro y Veracruz (Alvarado-Cárdenas y Ochoterena, 2007, Juárez-Jaimes et al., 2007). En Morelos se distribuye en los municipios de Cuernavaca, Jantetelco, Jiutepec, Miacatlán, Puente de Ixtla, Tepalcingo, Tepoztlán, Tlaquiltenango, Tlayacapan, Yautepec, Yecapixtla y Zacatepec. Fig. 3.

Esta planta crece en el bosque tropical caducifolio y en bosque de galería, en altitudes de 850 a $1870 \mathrm{~m}$, posee flores muy vistosas y tiene un gran potencial ornamental debido a que florece casi todo el año y fructifica entre abril y diciembre. El látex contiene un glucósido venenoso llamado tevetina, que se usa para matar insectos (McLaughlin et al., 1980; Laudadio y Davis, 2003).

Ejemplares examinados. Cuernavaca. Alrededores de Cuernavaca, jun 1965, Giral s.n. (ENCB); sin localidad, Lyonnet 3028 (MEXU); sin localidad, Rodríguez de la Sancha 55 (HUMO); campos de lava cerca de Cuernavaca, Pringle 6332 (MEXU); calzada de los Compositores (jardín del Ing. Giral), Vázquez 3296 (MEXU). Jantetelco. Amayuca, orilla de la carretera, Gutiérrez 309 (MEXU). Jiutepec. Estación Experimental de aprovechamiento de la vida silvestre "El Progreso", Quezada 1629 (MEXU, UAMIZ). Miacatlán. km 16 de la carretera Alpuyeca - Grutas, Alcántara 8 (UAMIZ). Puente de Ixtla. Tilzapotla, $3 \mathrm{~km}$ al SW, camino al cerro Frío, al W de "La Joya", Bonfil 211 (UAMIZ), Bonfil 325 (MEXU, UAMIZ); a 300 m del Comal, sobre carretera de terracería, Bustamante et al. 714 (HUMO); $5 \mathrm{~km}$ antes del Zapote, 18²8'35.04" N, 99²0'29.8" W, González-Rocha et al. 7 (UAMIZ); camino al Zapote, a 50 m en la subida al Mango, 18²9'14.2" N, 99²0'38.2" W, González-Rocha et al. 79 (UAMIZ); a $1 \mathrm{~km}$ al W de Tilzapotla, 18²8'40.3" N, 99¹7'09.1" W, Juárez y Bustamante 1135 (HUMO); camino a Tilzapotla, 18²9'21.8" N, 99²0'19.5" W, Ramírez et al. 964 (HUMO). Tepalcingo. Al S del Ejido El Limón, en las faldas del cerro Prieto, 18²9'38" N, 98³6'51" W, Almonte et al. 169 (HUMO); límites 
entre ejido El Limón - ejido Ixtlilco el Grande, al SE de la comunidad de El Limón, 18²9'17.1" N, 9855'25" W, Almonte et al. 265 (HUMO); en los límites entre El Limón e Ixtlilco el Grande, cerro arriba de un lugar llamado Los Guayabos, $B a$ rrera y Pacheco 170 (HUMO); $1 \mathrm{~km}$ al N de El Limón, cañada camino a la presa, Bonilla-Barbosa y López 1469 (FCME, HUMO, MEXU); 2 km al NE de El Limón, Bonilla-Barbosa y López 933 (HUMO); Ejido El Limón, Sierra Huautla, cerro El Pingo a $1 \mathrm{~km}$ NW del pueblo, Boyd et al. 6568 (HUMO); $1.75 \mathrm{~km}$ al W de El Limón, $18^{\circ} 32^{\prime} 0^{\prime \prime}$ N, 98 07'35" W, Cerros et al. 1620 (HUMO); $5 \mathrm{~km}$ al S de Los Sauces, camino Hutchila - El Limón, 18³6'48" N, 9855'57" W, Flores 245 (MEXU); 2.5 km al E de El Limón, 18³1'51" N, 9854'59" W, Juárez y Ramírez 343 (HUMO); en los cerros que limitan al ejido El Limón - ejido Ixtlilco El Grande, al SE de la comunidad El Limón, $18^{\circ} 28^{\prime} 52.8^{\prime \prime} \mathrm{N}, 98^{\circ} 55^{\prime} 12.8^{\prime \prime} \mathrm{W}$, Almonte et al. 427 (HUMO), Almonte et al. 456 (HUMO); $3.5 \mathrm{~km}$ al W de Ixtlilco El Grande, 18³1'40" N, 98 $52^{\circ} 55^{\prime \prime} \mathrm{W}$, Méndez et al. 184 (HUMO); junto al puente de entrada a Tepalcingo, Miranda 1367 (MEXU); sobre la vereda o camino al bordo, en el paraje La Cruz, Ramírez et al. 2337 (HUMO); en el pueblo de Tepalcingo, may 1941, Ramirez s.n. (MEXU). Tepoztlán. Santa Catarina, entrada a la parroquia 3 de Mayo, 8 may 1987, Beltrán s.n., Cordero s.n. (HUMO); San Andrés de la Cal, Ríos 25 (HUMO). Tlaquiltenango. $8 \mathrm{~km}$ al oriente de Ajuchitlán, 18²7'25.5" N, 9855'37.2" W, Castro y Villegas 1149 (HUMO); $4 \mathrm{~km}$ al oriente de Ajuchitlán, 18²8'03.7" N, 98 $58^{\circ} 53^{\prime \prime} \mathrm{W}$, Castro y Villegas 1195 (HUMO); 5-6 km al NW de Ajuchitlán, 18²8'59.2" N, 9857'46.6" W, Castro y Villegas 1233 (HUMO); 8 km al NW de Ajuchitlán, 18²9'36" N, 9858'20" W, Castro y Villegas 1107 (FCME, HUMO); $3.5 \mathrm{~km}$ al SE de Ajuchitlán, 18²7'27" N, 9856'32" W, Cerros et al. 685 (HUMO); $0.75 \mathrm{~km}$ al NW de Ajuchitlán, 18²8'1" N, 98 58'59" W, Cerros et al. 1203 (HUMO); en casa particular en la comunidad de Quilamula, 18³0'35" N, 9901'09" W, González-Rocha et al. 39 (UAMIZ); 1.5 $\mathrm{km}$ al N de Xantiopa, 18²6'11" N, 98 57'30" W, Maldonado et al. 1243 (HUMO), Maldonado et al. 1221 (HUMO); 1 km al W de Huaxtla, 18²2'54" N, 9903'13" W, Ramirez et al. 674 (HUMO); 2.25 km al NW de Huaxtla, 18²2'36" N, 9903'26" W, Ramirez et al. 1622b (HUMO). Tlayacapan. A $1.5 \mathrm{~km}$ de capilla de Tránsito colonia El Plan, cerro El Sombrerito ladera S, 1856’08" N, 98 $59^{\circ} 03^{\prime \prime}$ W, Cerros 12 (HUMO, UAMIZ); a $3 \mathrm{~km}$ al SW de Tlayacapan, sobre el camino Oaxtepec - Xochimilco, Lamy 141, M. A. Martínez 1888 y Zolla 27 (ENCB, MEXU); sin localidad, Rodriguez s.n. (FCME). Yautepec. $2 \mathrm{~km}$ al NW de Yautepec, carretera vieja Yautepec - Tepoztlán, 1849'44" N, 9903'09" W, Flores 121 (MEXU); carretera Yautepec - Amatlán, 1857'10.5" N, 9904'40" W, González-Rocha et al. 52 (UAMIZ); km 24 Atlihuayán, carretera Yautepec - Cuautla, 1852'06" N, 9905'04.1" W, González- 
Rocha et al. 53 (UAMIZ); al N de Oaxtepec, carretera que va a Xochimilco, Ishiki 1095 (MEXU); Monte Negro, $50 \mathrm{~m}$ abajo del ojo de agua El Altar, Miguel-Vázquez et al. 41 (UAMIZ); Zaragoza, esquina Jesús Avitia, colonia Progreso, Miguel-Vázquez et al. 43 (UAMIZ); Oaxtepec - Jardín botánico de Moctezuma, pasado el pueblo camino de El Bosque, Vázquez 256 (MEXU). Yecapixtla. $2.2 \mathrm{~km}$ de la carretera Yecapixtla - Achichipico, Anzúrez 143 (HUMO). Zacatepec. Zacatepec, 25 feb 1955, Fuentes s.n. (ENCB).

HAPLOPHYTON A. DC., Prodr. 8: 412-413. 1844.

Plantas herbáceas sufrutescentes; tallos cilíndricos, con látex blanco, pubescentes, coléteres intrapeciolares, diminutos e inconspicuos. Hojas alternas o subopuestas, pecioladas, sin coléteres en la lámina, láminas con pelos estrigosos, membranáceas. Flores solitarias, en ocasiones presentes en pares, terminales o axilares; brácteas florales escariosas; cáliz con sépalos iguales, foliáceos, puberulentos, sin coléteres en la base de la cara adaxial; corola hipocrateriforme, amarilla, sin corona anular, sin lóbulos coronales libres, prefloración dextrocontorta o sinistrocontorta, tubo floral sin crestas supra e infraestaminales, recto; estambres incluidos, anteras no conniventes ni aglutinadas a la cabeza estigmática, sin apéndices supra e infraestaminales; cabeza estigmática subglobosa, no lobulada en la base; gineceo apocárpico, bicarpelar, ovario súpero, nectario ausente. Fruto un folículo apocárpico, terete, adelgazándose hacia el ápice, peloso a glabro con la edad; semillas comosas en el ápice micropilar y calazal.

Género con dos especies propias del suroeste de los Estados Unidos, México, Guatemala y Belice, una de las cuales se distribuye en Morelos.

Haplophyton cimicidum A. DC., Prodr. 8: 412. 1844. Tipo: México, Oaxaca, Tehuantepec, Andrieux 250 (Lectotipo: G-DC, foto MEXU). Fig. 2C.

Haplophyton cinereum (A. Rich.) Woodson, Ann. Missouri Bot. Gard. 23(2): 231232. 1936. Echites cinereus A. Rich., Hist. Fís. Cuba, Bot., 11: 93. 1850. Tipo: Cuba, Crescit in insula Cuba, Ramón de la Sagra s.n. (Holotipo: P, Isotipo: US).

Nombres comunes registrados en la zona de estudio: hierba de la cucaracha, hierba del piojo, mata cucaracha.

Plantas herbáceas de 40-60 cm de altura; tallos cilíndricos, pubescentes, coléteres intrapeciolares de ca. $0.5 \mathrm{~mm}$ de largo. Hojas alternas, algunas veces 
subopuestas en ramas jóvenes, láminas ovado-elípticas, de 1.5-5.7 cm de largo $\times$ 0.7-3 cm de ancho, ápice acuminado, base obtuso-redondeada, estrigosas en ambas superficies, peciolos de 1.5-2.4 $\mathrm{mm}$ de largo, puberulentos. Flores solitarias, terminales o axilares, pedicelos de 4-9.5 mm de largo, puberulentos; brácteas florales verdes, lineares a lanceoladas, de 1-2 $\mathrm{mm}$ de largo $\times 0.5-1 \mathrm{~mm}$ de ancho, pilosas; cáliz con 5 sépalos verdes, filiformes, de 4-6.6 $\mathrm{mm}$ de largo $\times$ 0.3-0.5 $\mathrm{mm}$ de ancho, pubérulos, sin coléteres; corola infundibuliforme, dextrocontorta, amarilla, tubo de 7.5-10.5 mm de largo $\times 1.5-2 \mathrm{~mm}$ de diámetro, recto, lóbulos obovados a elípticos, de 1-1.5 cm de largo $\times 0.6-1 \mathrm{~cm}$ de ancho, redondeados en el ápice, ligeramente recurvados; estambres incluidos, filamentos libres, de ca. $1 \mathrm{~mm}$ de largo, anteras de 1.5-1.7 mm de largo, libres; cabeza estigmática de 1-1.2 mm de largo, estilo de 3-3.5 $\mathrm{mm}$ de largo; ovario de 1.4-1.5 mm de longitud, nectarios ausentes. Folículos verdegrisáceos, ligeramente falcados, de 7-12 cm de largo $\times$ 1.5-3 mm de ancho, pelosos; semillas de 6 a 10 por folículo, comosas, pardas, de $7.5-9 \mathrm{~mm}$ de largo $\times 1.3 \mathrm{~mm}$ de ancho, coma blanquecino, de 1.8-2 cm de largo.

Especie conocida del centro de México a Guatemala (Williams, 2009), el tipo es de Cuba. En nuestro país se conoce de Chiapas, Michoacán, Morelos, Oaxaca y Puebla (Juárez-Jaimes et al., 2007). En Morelos se ha colectado en Amacuzac, Ayala, Coatlán del Río, Cuernavaca, Emiliano Zapata, Jiutepec, Jojutla, Miacatlán, Puente de Ixtla, Tlalnepantla, Tlaquiltenango, Xochitepec y Yautepec. Fig. 3.

Haplophyton es el único género dentro de la subfamilia Rauvolfioideae que posee semillas con coma en ambos extremos y H. cimicidum es notable por la prefloración dextrocontorta de los lóbulos de la corola en la subfamilia (Williams, 1995). Esta planta se encuentra en el bosque tropical caducifolio y en bosque de galería en altitudes de 750 a $1700 \mathrm{~m}$. Florece entre febrero y diciembre y fructifica entre julio y diciembre. En Morelos se usan las hojas machacadas para matar algunos insectos (Snyder et al., 1958).

Ejemplares examinados. Amacuzac. Cerca de Teacalco, en las proximidades de Amacuzac, 1840'22" N, 99²9'34" W, Paray 3325 (ENCB). Ayala. Carretera Moyotepec, $3 \mathrm{~km}$ al S de Las Piedras, 18³9'6" N, 9859' $8^{\circ}$ W, Lott 295 (ENCB). Coatlán del Río. Camino hacia El Hoyanco, al lado del apantle, 1844'10.9" N, 99²6'05.7" W, González-Rocha et al. 57 (UAMIZ); sin localidad, Torres 401 (FCME, MEXU). Cuernavaca. 5 millas al S de Cuernavaca, Dixon 34 (MEXU); orilla del Río Po1lo, Palmira Chica, cerca de Temixco, 29 jun 1962, Sousa s.n. (MEXU). Emiliano Zapata. Tepetzingo, 1946'8.14" N, 9909'728" W, Flores-Morales 20 (HUMO). Jiutepec. Camino a la cañada del Cañón de lobos, colonia El Progreso, Sierra de Monte Negro, 1851'55.9" N, 99²'13.4" W, González-Rocha et al. 72 (UAMIZ), 
$18^{\circ} 51^{\prime} 52.4^{\prime \prime} \mathrm{N}, 9^{\circ} 07^{\prime} 54.08^{\prime \prime} \mathrm{W}$, camino a la cañada del Cañón de Lobos, colonia El Progreso, Sierra de Monte Negro, González-Rocha et al. 76 (UAMIZ), 1851'52.4" N, 9907'54.08" W, Miguel-Vázquez et al. 38 (UAMIZ). Jojutla. El Higuerón, campo de los lagartos, García 129 (MEXU); colonia Pedro Amaro, cerca del río Los Muros, Hernández 7 (HUMO), 30 sep 1987, Palacios s.n. (HUMO), Palacios 7 (HUMO); $3 \mathrm{~km}$ al S del centro del municipio (cuesta este del cerro), 18³5'20.8" N, 9909'10.4" W, Raz y Juárez 77 (HUMO); $2 \mathrm{~km}$ al S del centro del municipio, 18³5'20.8" N, 9909'10.4" W, Raz et al. 141 (HUMO); cerro El Higuerón, en la ladera S, Rivera 161 (MEXU); cerro, ladera N, Vázquez 417 (MEXU). Miacatlán. Carretera a Toluca, $8 \mathrm{~km}$ al NW de Miacatlán, 1849'37.7" N, 99²3'53.5" W, González-Rocha et al. 51 (UAMIZ); cerro Peña Colorada al W de la brecha Miacatlán - Palpan, Peñalosa 731 (MEXU); cerro de Las Cantinas II, al E de La Cucaracha, Miacatlán - Palpan, Peñalosa 779 (MEXU); cerro Peña Colorada, lado S de la Brecha Miacatlán - Palpan, Peñalosa 814 (MEXU). Puente de Ixtla. 2-3 km antes de Coaxitlán, 18²7'18.9" N, 99¹3'01.4" W, Bustamante et al. 143 (HUMO); 2-3 km al W antes de Coaxitlán vereda derecha, 18 ${ }^{\circ} 26^{\prime} 42.4^{\prime \prime} \mathrm{N}, 9^{\circ} 12^{\prime} 36.7^{\prime \prime} \mathrm{W}$, Bustamante et

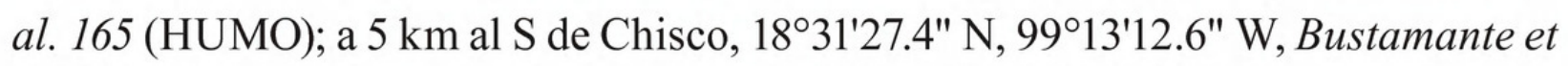
al. 233 (HUMO); $8 \mathrm{~km}$ al S de Chisco, 18³0'31" N, 99 ${ }^{\circ} 13^{\prime} 03.5^{\prime \prime} \mathrm{W}$, Castro et al. 1261 (HUMO); $2.5 \mathrm{~km}$ al W de la Granja El Abanico, $1 \mathrm{~km}$ antes de la entrada a Puente de Ixtla, $18^{\circ} 55^{\prime} 01^{\prime \prime} \mathrm{N}, 98^{\circ} 51^{\prime} 03^{\prime \prime} \mathrm{W}$, Flores 10 (MEXU); $3 \mathrm{~km}$ camino a Tilzapotla Coaxitlán, 18²7'35.2" N, 99¹3'22.6" W, Juárez et al. 1086 (HUMO); sin localidad, 25 ago 1955, Fuentes s.n. (ENCB, MEXU). Tlalnepantla. $1.5 \mathrm{~km}$ al W de Felipe Neri, Castillo 5600 (MEXU). Tlaquiltenango. 4 km al S de Coaxtitlán, 18²4'55.3" N, 99 $10^{\circ} 37^{\prime \prime} \mathrm{W}$, Betancourt et al. 89 (HUMO); $2 \mathrm{~km}$ al N de Huautla, 18²7'35" N, 99 $9^{\circ} 25^{\prime \prime} \mathrm{W}$, Castro 126 (HUMO); $1.25 \mathrm{~km}$ al E de Huautla, $18^{\circ} 26^{\prime} 13^{\prime \prime} \mathrm{N}, 99^{\circ} 2^{\prime} 0^{\prime \prime}$ W, Castro 250 (HUMO); $1.25 \mathrm{~km}$ al E de Huautla, $18^{\circ} 26^{\prime} 20^{\prime \prime} \mathrm{N}, 99^{\circ} 0^{\prime} 35^{\prime \prime} \mathrm{W}$, Castro $572 b$ (HUMO); 1 km al S de Rancho Viejo, 18²4'56.1" N, 9940'45.0" W, Castro 973 (HUMO); 2 km de Xochipala, 18²4'50" N, 99²'10" W, Cerros et al. 1082 (HUMO); autopista Cuernavaca - Acapulco km 149, Flores-Morales et al. 198 (HUMO), $1 \mathrm{~km}$

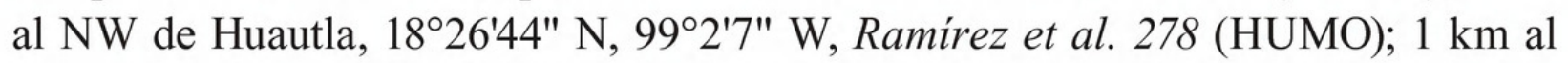
$\mathrm{S}$ de Huaxtla, 18²2'22" N, 99³'1" W, Juárez et al. 233 (HUMO); $4.5 \mathrm{~km}$ al N de Huautla, 18²6'37" N, 98 58'53" W, Maldonado y Castro 200 (HUMO); 3 km al SE de Ajuchitlán, 18²6'23" N, 9859'10" W, Maldonado y Castro 234 (HUMO); $2.5 \mathrm{~km}$ al SE de Xochipala, 18²4'5" N, 994'45" W, Ramirez et al. 487 (HUMO); $2.75 \mathrm{~km}$ al SE de Xochipala, 18²4'35" N, 994'20" W, Ramírez et al. 546 (HUMO); 3.75 al NE de Ajuchitlán, 18²7'55" N, 9859'1" W, Valdez et al. 551 (HUMO). Xochitepec. Palo Bolero, cerca de Cuernavaca, 19 nov 1955, Fuentes s.n. (ENCB, MEXU); Palo 
Bolero, cerca de Cuernavaca, 24 jun 1951, Rzedowski 216 (ENCB); sin localidad, sept 1934, Lyonnet 1064 (MEXU). Yautepec. Paraje El Fortín, Barranca Honda, 1849'30" N, 9906'13.3" W, Almonte 234 (HUMO); Cañón de Lobos 20 km al SE de Cuernavaca sobre la carretera Cuautla, Flores-Crespo 21 (ENCB); 6 millas de Yautepec, Lyons Jr. 115 (MEXU); Cañón de Lobos, 4 ago 1979, Sanjuan et al. s.n. (FCME), ibid., Vázquez 874 (MEXU).

LAUBERTIA A. DC., Prodr. 8: 486. 1844.

Lianas fruticosas o sufruticosas; tallos subcilíndricos a cilíndricos, con látex transparente, puberulentos o glabros, con coléteres intrapeciolares diminutos e inconspicuos. Hojas opuestas, pecioladas, sin coléteres en la lámina, láminas glabras a ligeramente puberulentas, membranáceas. Inflorescencia una cima escorpioide, axilar, subterminal o terminal; brácteas florales escariosas; cáliz con sépalos iguales, foliáceos, esparcidamente puberulentos a glabros, sin coléteres en la base de la cara adaxial; corola hipocrateriforme, de color violeta o vino, con una corona anular alrededor de la garganta del tubo, sin lóbulos coronales libres, prefloración dextrocontorta, tubo floral sin crestas supra e infraestaminales, retorcido debajo de la posición de las anteras; estambres exertos, anteras conniventes y unidas a la cabeza estigmática, sin apéndices supra ni infraestaminales; cabeza estigmática fusiforme o subcapitada, no lobulada en la base; gineceo apocárpico, bicarpelar, ovario súpero, rodeado de 5 nectarios. Frutos en folículos, apocárpicos, moniliformes, glabros a puberulentos; semillas comosas en el ápice micropilar.

Género con tres especies (Morales, 2002). Se distribuye en México, Guatemala, Belice, Colombia, Venezuela, Ecuador, Perú, Bolivia y Brasil (Morales, 2009). En México y en Morelos se conoce una especie.

Laubertia contorta (M. Martens \& Galeotti) Woodson, N. Amer. Fl. 29(2): 187. 1938. Haemadictyon contortum M. Martens \& Galeotti, Bull. Acad. Roy. Sci. Bruxelles 11(1): 360. 1844. Prestonia contorta (M. Martens \& Galeotti) Hemsl., Biol. Cent.-Amer., Bot. 2(10): 311. 1881. Tipo: México, Oaxaca, Zacatepec, Galeotti 1588 (Holotipo: BR). Fig. 2D.

Streptotrachelus pringlei Greenm., Proc. Amer. Acad. Arts 32(16): 298. 1897. Laubertia pringlei (Greenm.) Woodson, Ann. Missouri Bot. Gard. 18(4): 555. 1931. Tipo: México, Cuernavaca, Pringle 6554 (Holotipo: GH, Isotipo: MO).

Prestonia langlassei Standl., Contr. U.S. Natl. Herb. 23(4): 1159. 1924. Tipo: México, Michoacán, La Correa, Langlassé 435 (Holotipo: US). 
Lianas de 2 a $3 \mathrm{~m}$ de altura; tallos cilíndricos, puberulentos a glabros, coléteres intrapeciolares de ca. 1-1.5 mm de largo. Hojas opuestas, láminas elípticas a ovadoelípticas, de 5-11.3 cm de largo $\times 2.7-7.8 \mathrm{~cm}$ de ancho, ápice cortamente cuspidado o acuminado, base obtusa a ligeramente subcordada, haz puberulento y envés densamente pubescente, con marcada venación secundaria en el envés, peciolos de 5-7 mm de largo, pubescentes. Inflorescencia una cima escorpioide, axilar o terminal, con 5 a 15 flores, pedúnculo de $1.7-2.3 \mathrm{~cm}$ de largo, pubescente, pedicelo de $9-13 \mathrm{~mm}$, pubescente; brácteas florales escariosas, lanceoladas o filiformes, de 1-2.5 mm de largo $\times$ de ca. $0.5 \mathrm{~mm}$ de ancho, pubescentes; cáliz con 5 sépalos verdes, ovado-lanceolados, de 3-4 mm de largo $\times 1 \mathrm{~mm}$ de ancho, acuminados a largamente acuminados, puberulentos, coléteres ausentes; corola hipocrateriforme, de color violeta, tubo de 1.8-2.1 mm de largo $\times 2-3 \mathrm{~mm}$ de diámetro, retorcido por debajo de los estambres, lóbulos obovados, de 7.5-10 mm de largo $\times$ 5-7.5 $\mathrm{mm}$ de ancho, redondeados, reflexos, corona anular entera, de ca. $1 \mathrm{~mm}$ de largo; estambres incluidos, filamentos libres, de ca. $1.2 \mathrm{~mm}$ de largo, anteras de 6-7 $\mathrm{mm}$ de largo, fusionadas a la cabeza estigmática; cabeza estigmática de 1.5-2 mm de largo, estilo de 1.2-1.6 cm de largo; ovario de ca. 1.5-2 mm de largo, rodeado por 5 nectarios más pequeños que el ovario, de 1-1.8 mm de largo. Folículos verdes, moniliformes, de 20-25 cm de largo $\times$ 0.4-0.5 cm de diámetro, puberulentos; semillas comosas, de 14-16 mm de largo, coma blanquecino, de ca.1.5 cm de largo.

Especie endémica de México, conocida de los estados de Chihuahua, Colima, Guerrero, Jalisco, Estado de México, Michoacán, Morelos, Oaxaca, Puebla y Sinaloa (Juárez-Jaimes et al., 2007). En Morelos se distribuye en los municipios de Cuernavaca, Tlaquiltenango y Jantetelco. Fig. 3.

Planta que crece en bosque tropical caducifolio, en altitudes de 950 a 1450 $\mathrm{m}$. Se ha colectado con flores en agosto y septiembre y con frutos en septiembre, octubre y diciembre. En el estado no se había recolectado desde 1995, sin embargo gracias a la búsqueda en las localidades reportadas, se comprobó su presencia en el municipio de Jantetelco. Morales (2002, 2009) y Diego-Pérez (2004) señalan que los estambres son exsertos o ligeramente así, mientras que en los ejemplares examinados en la entidad son inclusos.

Ejemplares examinados. Cuernavaca. Campos de lava cerca de Cuernavaca, Pringle 6554 (MEXU). Tlaquiltenango. $1.5 \mathrm{~km}$ al SE de Huaxtla, 18²2'30" N, 99³'22" W, Cerros et al. 1350 (HUMO); $1.75 \mathrm{~km}$ al S Huaxtla, 18²1'48" N, 99²'30" W, Cerros y Flores 1578 (HUMO). Jantetelco. Pirámides de Chalcatzingo al S y al W del cerro Garambullo, 18³0'0" N, 9957'28" W, Ramírez 804 (HUMO); 0.43 km al SE de las pirámides de Chalcatzingo, entre los cerros Delgado y Chalcatzingo, 1840'27.2" N, 9846'02.7" W, González-Rocha et al. 84 (UAMIZ); 0.5 km al SE de 
las pirámides de Chalcatzingo, entre los cerros Delgado y Chalcatzingo, 1840'28.31" N, 9846'03.20" W, González-Rocha et al. 85 (UAMIZ).

MANDEVILLA Lindl., Edwards's Bot. Reg. 26: t. 7.1840.

Subarbustos o lianas; tallos aplanados, cilíndricos o subcilíndricos, con látex blanco, glabros, puberulentos o pubescentes, con coléteres interpeciolares pequeños e inconspicuos. Hojas opuestas, pecioladas, con coléteres en la lámina, distribuidos a lo largo de la vena media o agrupados en la base de la cara adaxial, láminas pubescentes a glabras, membranáceas. Inflorescencia racemosa, axilar o terminal, con pocas o muchas flores, a veces aglomeradas; brácteas florales foliáceas o escariosas; cáliz con sépalos iguales, foliáceos, glabros a pubescentes, con numerosos coléteres dispuestos en la base de la cara adaxial; corola infundibuliforme o hipocrateriforme, amarilla, rosada, roja o blanca, sin corona anular, sin lóbulos coronales libres, prefloración dextrocontorta, tubo floral sin crestas supra e infraestaminales, recto, giboso o ventricoso en la base; estambres incluidos, anteras conniventes y unidas a la cabeza estigmática, sin apéndices supra e infraestaminales; cabeza estigmática pentagonal, no lobulada en la base; gineceo apocárpico, bicarpelar, ovario súpero, rodeado de 2 a 5 nectarios, o éstos raramente ausentes. Frutos en folículos, apocárpicos, a veces unidos en el ápice, teretes a submoniliformes, puberulentos o glabros; semillas comosas, con un mechón de pelos en el ápice micropilar.

Género con cerca de 172 especies distribuidas desde México hasta el norte de Argentina y las Antillas. En el país se registran 22 taxa nativos y de Morelos se conocen tres.

Clave para la determinación de especies de Mandevilla

1 Láminas de las hojas con coléteres distribuidos a lo largo de la vena media de la cara adaxial; el tubo de la corola giboso o ventricoso en la base ... M. subsagittata

1 Láminas de las hojas con coléteres agrupados en la base de la vena media de la cara adaxial; el tubo de la corola recto en la base

2 Lianas; hojas con el haz hirsuto; lóbulos de la corola erectos; folículos de 16$24 \mathrm{~cm}$ de largo M. holosericea

2 Subarbustos erectos o escandentes; hojas con el haz glabro; lóbulos de la corola extendidos y reflexos; folículos de 7-11 cm de largo M. foliosa

Mandevilla foliosa (Müll. Arg.) Hemsl., Biol. Cent.-Amer., Bot. 2(10): 316. 1881. Amblyanthera foliosa Müll. Arg., Linnaea 30(4): 427-428. 1860. Laseguea foliosa 
(Müll. Arg.) Miers, Apocyn. S. Am. 253. 1878. Tipo: México, cerca de la ciudad de México, Ghiesbreght s.n. (Holotipo: G). Fig. 2E.

Echites apocynifolius A. Gray, Proc. Amer. Acad. Arts 22: 435. 1887. Mandevilla apocynifolia (A. Gray) Woodson, Ann. Missouri Bot. Gard. 19(1): 65. 1932. Tipo: México: Jalisco: Río Blanco, Palmer 734 (Holotipo: GH).

Subarbustos erectos o escandentes de 0.7-4 m de altura; tallos cilíndricos, glabros, coléteres interpeciolares de ca. $0.5 \mathrm{~mm}$ de largo, estípulas de 1.5-3.5 mm de largo, pubescentes. Hojas opuestas, láminas con coléteres agrupados en la base de la vena media de la cara adaxial, elípticas a obovado-elípticas, de 3-14.5 cm de largo $\times 1-5.2 \mathrm{~cm}$ de ancho, ápice acuminado, base cordada o algunas veces subcordada, haz glabro, envés puberulento, con marcada venación secundaria solo en el envés, membranáceas, peciolos de 4-13 $\mathrm{mm}$ de largo, glabros a esparcidamente puberulentos. Inflorescencia un racimo axilar de 3 a 5 flores, pedúnculo de 2.5-4.5 $\mathrm{mm}$ de largo $\times 1-1.2 \mathrm{~mm}$ de diámetro, glabro, pedicelo de 8-14 mm de largo, algunas veces contorneado, glabro; brácteas florales verdes, lanceoladas a filiformes, de 6.5-8.5 mm de largo $\times$ 0.2-0.8 $\mathrm{mm}$ de ancho, esparcidamente puberulentas en el margen; cáliz con 5 sépalos verdes, filiformes, de 5-7 $\mathrm{mm}$ de largo $\times$ 0.4-0.7 $\mathrm{mm}$ de ancho, esparcidamente puberulentos, coléteres ausentes; corola hipocrateriforme, amarilla; tubo recto, de 10-14 $\mathrm{mm}$ de largo $\times 1.6-2.6 \mathrm{~mm}$ de diámetro, diminutamente engrosado donde se insertan los estambres, lóbulos obovados, de 7-9 $\mathrm{mm}$ de largo $\times$ 3-4.6 mm de ancho, extendidos y reflexos; anteras de 2.5-3 mm de largo, fusionadas a la cabeza estigmática; cabeza estigmática de 1.8-2 $\mathrm{mm}$ de largo, estilo de 2.5-3 mm de largo; ovario de ca. $1 \mathrm{~mm}$ de largo, rodeado por 5 nectarios, libres, más largos que el ovario, de 1.3-1.7 mm de largo. Folículos verdes, pardos al madurar, unidos en el ápice antes de la maduración, falcados, submoniliformes, de 7-11 $\mathrm{cm}$ de largo $\times$ 2.5-3.5 mm diámetro, glabros a pubescentes; semillas 6 por folículo, comosas, pardas, de 9.5-12 mm de largo $\times 1-1.7 \mathrm{~mm}$ de ancho; el coma amarillo, de 2-3 cm de largo.

Especie endémica de México, distribuida en los estados de Chihuahua, Colima, D.F., Durango, Guanajuato, Guerrero, Hidalgo, Jalisco, México, Michoacán, Nayarit, Querétaro, Sinaloa, Sonora y Veracruz (Juárez-Jaimes et al., 2007, Alvarado-Cárdenas y Morales 2014). En Morelos se conoce de Cuernavaca, Jiutepec, Puente de Ixtla, Tepalcingo, Tepoztlán y Tlayacapan. Fig. 3.

Planta abundante en el estado que se distribuye en bosque tropical caducifolio y en bosque de coníferas, en altitudes de 1200 a $1900 \mathrm{~m}$. Se registra en floración de junio a octubre y en fructificación en junio y diciembre. 
Ejemplares examinados. Cuernavaca. Avenida Ahuatlán, entrando a Lomas de Zompantle, $18^{\circ} 57^{\prime} 5.3^{\prime \prime}$ N, 99¹5'20.8" W, Flores-Morales 124 (HUMO); a un costado del Polideportivo de la Universidad Autónoma del Estado de Morelos, 1859'8" N, 99¹4'9.4" W, Flores-Morales 129 (HUMO); La Carpa, a 2 km de la entrada por la carretera de Otongo, carretera Cuernavaca - Buena Vista del Monte, 18 ${ }^{\circ} 57^{\prime} 13^{\prime \prime}$ N, 99¹7'5" W, González-Rocha et al. 45, 46 (UAMIZ), Miguel-Vázquez et al. 24, 26 (UAMIZ); camino a Cuentepec, 1853'29.7" N, 99²0'3.3" W, González-Rocha et al. 49 (UAMIZ); barranca a $2.4 \mathrm{~km}$ al NE de El Rancho Flowers, $18^{\circ} 56^{\prime} 14.2^{\prime \prime} \mathrm{N}$, 99¹6'24.6" W, González-Rocha et al. 66, 68 (UAMIZ); barranca a $2.4 \mathrm{~km}$ al NE de El Rancho Flowers, 1856'13.2" N, 99¹6'17.7" W, González-Rocha et al. 67 (UAMIZ); barranca a $2.4 \mathrm{~km}$ al NE de El Rancho Flowers, 1856' $9^{\prime \prime} \mathrm{N}, 9^{\circ} 16^{\prime 20.2 " ~ W, ~}$ González-Rocha et al. 68 (UAMIZ); en campo de lava, km 15, hacia el camino de Yautepec - Cuernavaca, Lundell 12499 (MEXU); Lomas de Tetela del Monte, Lyonnet 64 (MEXU); Salto de San Antonio, Matuda 21604 (MEXU); entre Santa Catarina y Ahuatepec, Medina 170 (MEXU, UAMIZ); cerca de 4 millas al E de Ocotepec, carretera Cuernavaca - Tepoztlán, Stevens 1380 (ENCB). Jiutepec. Monte Negro, $18^{\circ} 51^{\prime} 10.6^{\prime \prime} \mathrm{N}, 9^{\circ} 8^{\prime} 7.8^{\prime \prime} \mathrm{W}$, Flores-Morales 9 (HUMO); Monte Negro, 1852'0" N, 99 ${ }^{\circ} 0^{\prime}$ " W, Salazar 16 (HUMO); Texcal, Tejalpa, 7 km carretera Cuernavaca - Tepoztlán, Vázquez 1695 (ENCB); Texcal de Santa Catarina, km 7 carretera a Tepoztlán, lechos de lava, Vázquez 2973 (MEXU). Puente de Ixtla. Tilzapotla, $2.5 \mathrm{~km}$ al SW camino al Cerro Frío, Bonfil 192, 357 (UAMIZ); a $300 \mathrm{~m}$ del Comal, sobre carretera de terracería, Bustamante 694 (HUMO); en la comunidad del Zapote, 18²8'1.08" N, 99¹9'23.5" W, González-Rocha et al. 80 (UAMIZ). Tepalcingo. Límites entre el ejido Limón - Ixtlilco El Grande, al SE de la comunidad, 18²9'17.3" N, 9855'16.9" W, Almonte 339 (HUMO); 3 km al SE de El Limón, 18³1'8" N, 9854'35" W, Ramirez et al. 759 (HUMO, MEXU); $2.5 \mathrm{~km}$ al NE de El Limón de Cuachichinola, 18³2'22" N, 9854'55" W, Valdez 54 (HUMO). Tepoztlán. Aguilillas, $15 \mathrm{~km}$ de la carretera Cuernavaca - Tepoztlán, Crespo 41 (ENCB); Amatlán de Quetzalcóatl, 6 sep 1987, Galindo s.n. (HUMO, UAMIZ); Amatlán de Quetzalcóatl, 1858'37.94" N, 99³'34.04" W, Escalante 19 (HUMO); Amatlán de Quetzalcóatl, hacia el NW, $18^{\circ} 59^{\prime} 0^{\prime \prime} \mathrm{N}, 9^{\circ} 2^{\prime} 30^{\prime \prime} \mathrm{W}$, Espejo y Chehaibar 2549 (MEXU, UAMIZ); cima del cerro de la Cruz, 1857'54.6" N, 996'51.6" W, Flores-Morales 120 (HUMO); Pedregal, Tepozteco, Lyonnet 1 (MEXU), Rzedowski 1166 (ENCB); Cueva del Diablo, 2 km al S de Ocotitlán, Ortiz 565 (FCME); Sierra de Chalchi, cerca de Tepoztlán, Paray 1633 (ENCB); Tepoztlán a Yautepec 4 km, Saiki 457 (MEXU); Chisto, Vázquez 2290 (ENCB, MEXU); a $0.7 \mathrm{~km}$ al SE de San Andrés de la Cal, 1857'09.5" N, $99^{\circ} 06^{\prime} 32.8^{\prime \prime} \mathrm{W}$, González-Rocha et al. 156 (UAMIZ). Tlayacapan. $0.5 \mathrm{~km}$ de la ca- 
pilla del Tránsito, colonia El Plan, cerro El sombrerito, ladera N, Cerros 44 (HUMO, UAMIZ); huertas pasando el pueblo, Vázquez 1695 (HUMO).

Mandevilla holosericea (Sessé \& Moc.) J. K. Williams, Sida 18(1): 237. 1998. Echites holosericeus Sessé \& Moc., Naturaleza (Mexico City), ser. 2, 2, app. 45. 1893. Tipo: México, Michoacán, Sessé \& Mociño 5073 (Holotipo: MA). Fig. 2F.

Mandevilla sertuligera Woodson, Ann. Missouri Bot. Gard. 19(4): 383-384. 1932. Tipo: México, Michoacán, Pringle 13890 (Holotipo: US; Isotipo: MO).

Mandevilla syrinx Woodson, Ann. Missouri Bot. Gard. 19(1): 53-54. 1932. Tipo: México, Jalisco, Pringle 5422 (Holotipo: MO; Isotipo: MEXU).

Lianas de 2-3 m de largo; tallos subcilíndricos, pilosos, coléteres interpeciolares de ca. $1 \mathrm{~mm}$ de largo. Hojas opuestas, láminas con coléteres agrupados en la base de la vena media de la cara adaxial, elípticas a obovadas, de $2.5-9.5 \mathrm{~cm}$ de largo $\times 1-4.5 \mathrm{~cm}$ de ancho, ápice largamente acuminado, base cordada o subcordada, haz hirsuto, envés tomentoso, con marcada venación secundaria en ambas superficies, especialmente en el envés, membranáceas, peciolos de 3-9.5 $\mathrm{mm}$ de largo, hirsutos. Inflorescencia un racimo axilar o terminal, de pocas a hasta 20 flores, a veces muy congestionadas, pedúnculo de 0.7-3 $\mathrm{cm}$ de largo $\times 6-7 \mathrm{~mm}$ de ancho, pubescente, pedicelo de 4-7 $\mathrm{mm}$ de largo, puberulento; brácteas florales verdes, lanceoladas, de 3.5-8.5 mm de largo $\times$ 0.2-0.7 $\mathrm{mm}$ de ancho, pilosas; cáliz con 5 sépalos verdes, lanceolados a filiformes, de 5-7 $\mathrm{mm}$ de largo $\times 0.5-1 \mathrm{~mm}$ de ancho, puberulentos; corola hipocrateriforme, amarillo-verdosa, tubo recto, de 7.5-10 $\mathrm{mm}$ de largo $\times 2.5$ $3.5 \mathrm{~mm}$ de diámetro, lóbulos obovados, de 4-6 mm de largo $\times$ 2-3 $\mathrm{mm}$ de ancho, erectos, a veces extendidos; estambres incluidos, filamentos de ca. $1 \mathrm{~mm}$ de largo, anteras de 3-4.5 mm de largo, fusionadas a la cabeza estigmática; ésta de 2-3 $\mathrm{mm}$ de largo, estilo de 3-4.5 mm de largo; ovario de ca. 1.12-1.3 $\mathrm{mm}$ de largo, rodeado por 5 nectarios libres, más largos que el ovario, de ca. $2 \mathrm{~mm}$ de largo. Folículos verdes, pardos al madurar, falcados, generalmente lisos, a veces submoniliformes cuando maduran, de 16-24 cm de largo $\times 1.5-3.5 \mathrm{~mm}$ de diámetro, glabros a pubescentes; semillas de hasta 10 por folículo, comosas, pardas, de 7.5-10 mm de largo $\times 1.4-1.8$ $\mathrm{mm}$ de diámetro, coma blanquecino a amarillento, de 2.6-2.7 $\mathrm{cm}$ de largo.

Especie endémica de México que se distribuye en Chiapas, Colima, Guanajuato, Guerrero, Hidalgo, Jalisco, México, Michoacán, Morelos, Nayarit, Nuevo León, Puebla, Querétaro, San Luis Potosí, Sinaloa, Sonora, Tamaulipas y Zacatecas (Juárez-Jaimes et al., 2007). En Morelos se conoce de Cuernavaca, Tepoztlán y Tlayacapan. Fig. 3. 
Especie reportada en el norte del estado donde se distribuye en los bosques húmedos de coníferas y Quercus, en altitudes de 1500 a $1900 \mathrm{~m}$. Se ha colectado con flores en junio y diciembre y con frutos en junio y octubre. Woodson (1933) utilizó el tipo de inflorescencia y la longitud de los sépalos para definir a las especies mexicanas de Mandevilla que tienen lóbulos erectos y reconoció dos: M. syrinx Woodson y M. sertuligera Woodson. Morales (1998) reportó que el tamaño del cáliz y el tipo de inflorescencia son muy variables y consideró a $M$. sertuligera como sinónimo de M. syrinx, pero el nombre correcto para ambas especies de acuerdo con Williams (1998a) es M. holosericea por el principio de prioridad. En este estudio se siguió el criterio de Williams (1998a), ya que esta especie muestra variabilidad en los caracteres antes mencionados.

Ejemplares examinados. Cuernavaca: Barranca Lomas de Zompantle, Flores-Morales 176 (HUMO); excursión Zempoala - Tetecala, Lyonnet 42 (MEXU); Barranca Zompantle y linderos, cerca de L'Amagatall, Vázquez 1227 (MEXU); Barranca del L'Amagatall, Vázquez 1838 (MEXU); $1.51 \mathrm{~km}$ al SW de Lomas del Sol (en línea recta), barranca La Tilapeña, 1857'22.3" N, 99¹7'25.6" W, González-Rocha et al. 266 (UAMIZ). Tepoztlán. Área recreativa del Parque Nacional El Tepozteco, Estrada 1020 (MEXU, UAMIZ). Tlayacapan. $1.15 \mathrm{~km}$ al W de San José de Los Laureles, subiendo al cerro Popotlán, 1858'46.6" N, 990'48" W, González-Rocha et al. 47 (UAMIZ); al S de la barranca Tepecapa, 1857'29.7" N, 990'44.4" W, Hernández-Cárdenas et al. 255 (UAMIZ); al N de la barranca Tepecapa, a $1.7 \mathrm{~km}$ al SW de San José de Los Laureles, 1858'6.7" N, 99¹'0.2" W, Hernández-Cárdenas et al. 409 (UAMIZ), Hernández-Cárdenas et al. 475 (UAMIZ).

Mandevilla subsagittata (Ruiz \& Pav.) Woodson, Ann. Missouri Bot. Gard. 19(1): 69-70. 1932. Echites subsagittatus Ruiz \& Pav., Fl. Peruv. 2: 19. 1799. Tipo: Perú, sin localidad, Ruiz \& Pavón s.n. (Holotipo: MA). Fig. 2 G.

Echites secundiflorus A. DC., Prodr. 8: 457. 1844. Temnadenia secundiflora (A. DC.) Miers, Apocyn. S. Am. 211. 1878. Tipo: México, ícono Sessé et Mociño, colección Torner 0801! Hunt Institute for Botanical Documentat.

Echites jasminiflorus M. Martens \& Galeotti, Bull. Acad. Roy. Sci. Bruxelles 11(1): 357-358. 1844. Mesechites jasminiflorus (M. Martens \& Galeotti) Miers, Apocyn. S. Am. 235. 1878. Tipo: México, Oaxaca, sin localidad, Galeotti 1602 (Holotipo: BR). Echites secundus Sessé \& Moc., Fl. Mexic. 44. 1887[1893]. Tipo: México, sin localidad, Sessé \& Mociño 5174 (Lectotipo: MA, designado por Morales, 1998).

Echites cuspidifera S. F. Blake, Contr. Gray Herb. 52: 79. 1917. Tipo: Belice; Cayo, pine ridge near Manatee Lagoon, 11 jun 1905, Peck 35 (Holotipo: GH). 


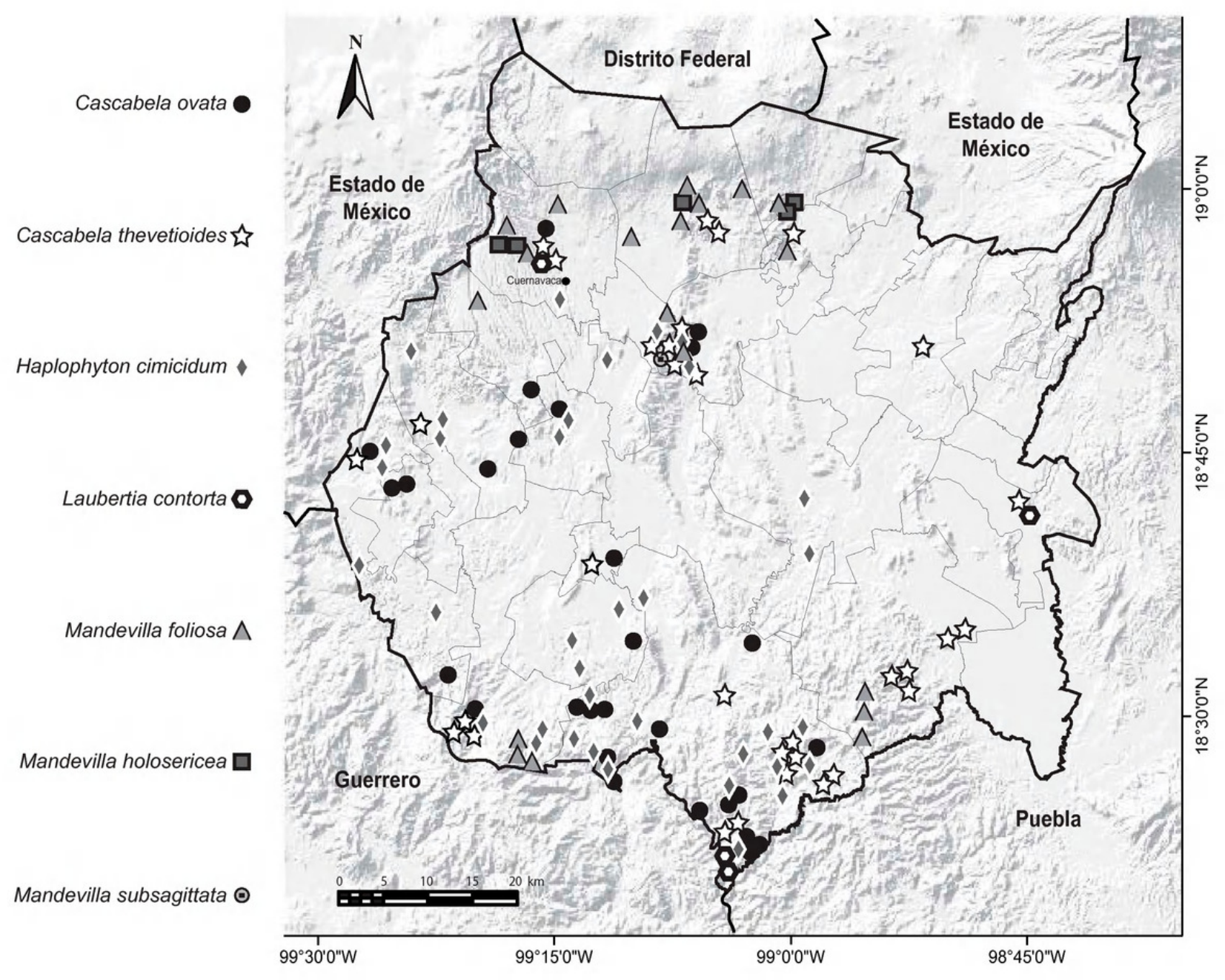

Fig. 3. Distribución de las especies de Cascabela, Haplophyton, Laubertia y Mandevilla en el estado de Morelos.

Lianas sufrutecentes de 2-5 m de altura; tallos subcilíndricos, pubescentes, coléteres interpeciolares de ca. $1 \mathrm{~mm}$ de largo. Hojas opuestas, láminas con coléteres distribuidos a lo largo de la vena media de la cara adaxial, elípticas, de 5-7.5 $\mathrm{cm}$ de largo $\times 2-4 \mathrm{~cm}$ de ancho, ápice cuspidado a mucronado, base auriculada-subsagitada, haz densamente pubescente, envés hirsuto, con marcada venación secundaria en el haz, membranáceas, peciolos de 3-8 $\mathrm{mm}$ de largo, hirsutos a híspidos. Inflorescencia un racimo axilar de 8 a 20 flores, pedúnculo de 0.9-3.6 $\mathrm{cm}$ de largo, pubescente, pedicelo de 3-7 $\mathrm{mm}$ de largo, pubescentes; brácteas florales verdes, lanceoladas, de 1-5 mm de largo $\times 1-2 \mathrm{~mm}$ de ancho, pubescentes; cáliz con 5 sépalos verdes, ovados, de 2.5-3.5 mm de largo $\times$ 0.5-1 $\mathrm{mm}$ de ancho, pubescentes, coléteres ausentes; corola hipocrateriforme, amarilla con la garganta anaranjada-rojiza, de 2-2.5 $\mathrm{cm}$ de largo $\times 2-3 \mathrm{~mm}$ de diámetro, 
tubo giboso o ventricoso en la base, lóbulos oblicuamente obovados a oblongos, de 1-1.5 cm de largo $\times 6-9 \mathrm{~mm}$ de ancho, reflexos; estambres incluidos, anteras de 4-5 $\mathrm{mm}$ de largo, fusionadas a la cabeza estigmática; cabeza estigmática de 1.8-2 mm de largo, estilo de 1.2-2.3 cm de largo; ovario de ca. 1-2 mm de largo, rodeado por 5 nectarios libres, más largos que el ovario, de 1.3-1.7 $\mathrm{mm}$ de largo. Folículos falcados, moniliformes, de 10-20 cm de largo $\times 2.8-3 \mathrm{~mm}$ de diámetro, glabros; semillas comosas, pardas, de 6-7 $\mathrm{mm}$ de largo, coma pardo claro de 15$20 \mathrm{~mm}$ de largo.

Se distribuye en México, Guatemala, Belice, El Salvador, Honduras, Costa Rica, Ecuador, Colombia, Perú, Venezuela y el Caribe. En México se conoce de los estados de Campeche, Chiapas, Guerrero, Hidalgo, Jalisco, Michoacán, Morelos, Nayarit, Oaxaca, Puebla, Querétaro, Quintana Roo, San Luis Potosí, Sinaloa, Tabasco, Tamaulipas, Veracruz, Yucatán (Juárez-Jaimes et al., 2007). En Morelos solo se registra en el municipio de Yautepec. Fig. 3.

Esta especie crece en el bosque tropical caducifolio en altitudes de 1400 a $1500 \mathrm{~m}$. Solo se ha colectado floreciendo en octubre. Mandevilla subsagittata se distingue por la presencia de coléteres dispuestos a lo largo de la vena media y por tener la corola con tubo giboso o ventricoso. Para el estado se reporta un ejemplar de Miranda 1653 (MEXU) de 1941 y no se ha recolectado nuevamente, probablemente esta planta sea escasa o bien, sus poblaciones hayan sido perjudicadas debido al impacto de la urbanización en la vegetación en el Cañón de Lobos.

Ejemplares examinados. Yautepec. Cañón de Lobos, Miranda 1653 (MEXU).

\section{PLUMERIA L., Sp. Pl. 1: 209. 1753.}

Arbustos o árboles, con látex blanco; tallos teretes, con cicatrices al caducar las hojas, glabros, con coléteres intrapeciolares diminutos e inconspicuos. Hojas alternas, dispuestas en espiral, pecioladas, sin coléteres en la lámina, láminas glabras o pilosas, firmemente membranáceas a subcoriáceas. Inflorescencia un corimbo o un racimo de corimbos, terminal, a veces congestionada, pedúnculo a veces muy largo y ramificado; brácteas florales escariosas; cáliz con sépalos iguales, más o menos diminutos, glabros, sin coléteres en la base de la cara adaxial; corola hipocrateriforme, blanca o rosada con la garganta amarilla, sin corona anular, sin lóbulos coronales libres, prefloración sinistrocontorta, tubo floral sin crestas supra e infraestaminales, recto; estambres incluidos, anteras no conniventes ni aglutinadas a la cabeza estigmática, sin apéndices supra e infraestaminales; cabeza estigmática bicapitada, no lobulada en la base; gineceo apocárpico, bicarpelar, ovario semiín- 
fero, nectarios ausentes. Frutos en folículos, apocárpicos, teretes, glabros; semillas aladas y planas.

Género con ocho o nueve especies distribuidas desde México hasta Brasil, Bolivia y las Antillas. Para México y en Morelos se conoce una.

Plumeria rubra L., Sp. Pl. 1: 209-210. 1753. Tipo: Sloane, Voy. Jamaica 2: 61, t. 185, f. 1 (Lectotipo designado por Wijnands, 1983. Bot. Commelins 44. A. A. Balkema, Rotterdam). Fig. 4A.

Plumeria mollis Kunth, Nov. Gen. Sp. (quarto ed.) 3: 230. 1818[1819]. Tipo: Venezuela, Insulae Panumane (Misiones del Orinoco), Humboldt \& Bonpland s.n. (Holotipo: P-HB).

Plumeria rubra fo. acutifolia (Poir.) Woodson, Ann. Missouri Bot. Gard. 25(1): 211. 1938[1937]. Plumeria acutifolia Poir., Encyclopédie Méthodique. Encycl., Suppl. 2(2): 667. 1812. Tipo: México, sin localidad, sin colector s.n. (Holotipo: P).

Plumeria megaphylla A. DC., Prodr. 8: 391. 1844. Tipo: México, Puebla, Chila, Andrieux 257 (Holotipo: G-DC, foto ENCB).

Nombres comunes registrados en la zona: cacaloxóchitl, cacaloxúchitl, flor de chacal, flor de mayo.

Árboles o arbustos de 1.5-6 m de altura; tallos teretes, suberosos, glabros, coléteres intrapeciolares de menos de $1 \mathrm{~mm}$ de largo. Hojas alternas, conglomeradas al final de las ramas, láminas oblongo-elípticas a obovado-elípticas, de 11-32 cm de largo $\times 2.5-10 \mathrm{~cm}$ de ancho, ápice largamente acuminado, base cuneada, haz glabro, envés pubescente a glabro, con marcada venación secundaria en ambas superficies, membranáceas a subcoriáceas, peciolos de 1.5-5.8 cm de largo, glabros a pubescentes. Inflorescencia un corimbo terminal, de hasta 30 flores, pedúnculo de 2.5-10.5 $\mathrm{cm}$ de largo, glabro a pubescente, pedicelo de $1.5-3 \mathrm{~cm}$ de largo, glabro a esparcidamente puberulento; brácteas florales escariosas, ovadas a oblongo-ovadas, de 1.7-3 $\mathrm{mm}$ de largo $\times 2-3 \mathrm{~mm}$ de ancho, glabras; cáliz con 5 sépalos escariosos, ovados u oblongos, de 2-5 mm de largo $\times 1-2 \mathrm{~mm}$ de ancho, glabros, coléteres ausentes; corola hipocrateriforme, blanca o rosada con tonalidades amarillas en la garganta, tubo recto, de 1.3-1.7 cm de largo $\times$ 1.5-3 mm de diámetro, lóbulos obovados, de 1.8-3.2 $\mathrm{cm}$ de largo $\times$ 0.6-1.4 cm de ancho, redondeados, ligeramente recurvados; estambres incluidos, filamentos libres, de ca. $1 \mathrm{~mm}$ de largo, anteras de ca. $2 \mathrm{~mm}$ de largo, libres de la cabeza estigmática; cabeza estigmática de ca. 1-1.5 mm de largo, estilo de ca. $1 \mathrm{~mm}$ de largo, ovario de ca. $1 \mathrm{~mm}$ de largo, nectarios ausentes. Folículos verde- 
González-Rocha y Cerros-Tlatilpa: Apocynaceae en el estado de Morelos
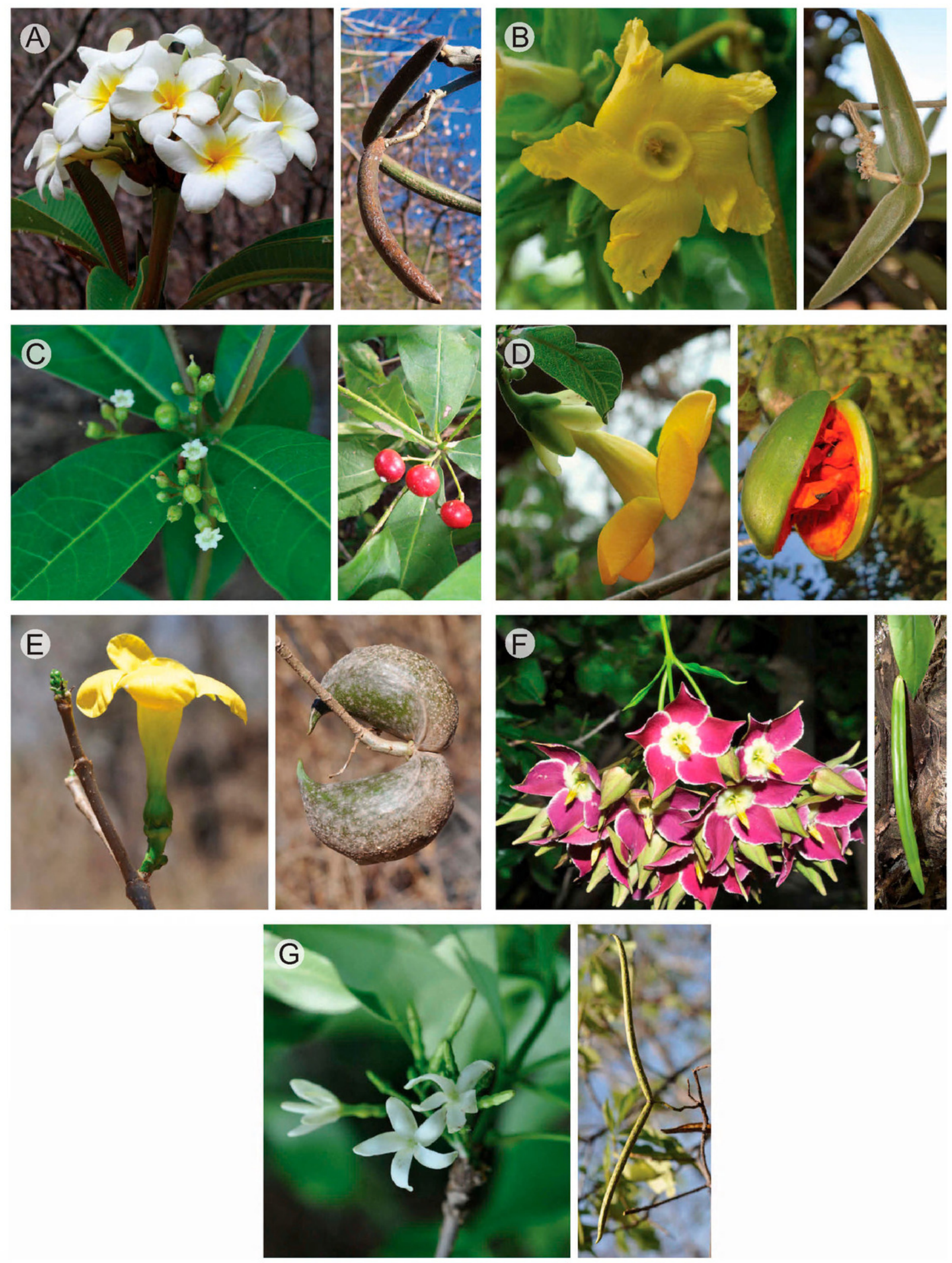

Fig. 4. Flores y frutos de Plumeria, Prestonia, Rauvolfia, Tabernaemontana, Thenardia y Tonduzia. A. Plumeria rubra; B. Prestonia mexicana; C. Rauvolfia tetraphylla; D. Tabernaemontana glabra; E. T. tomentosa; F. Thenardia floribunda; G. Tonduzia longifolia. 
amarillentos a pardos oscuros al madurar, teretes, de 6.8-18 $\mathrm{cm}$ de largo $\times$ 0.8-1.4 $\mathrm{cm}$ de diámetro, glabros; semillas pardas claras, de 1-1.6 $\mathrm{cm}$ de largo $\times 5-10 \mathrm{~mm}$ de ancho, ala de $1.6-2.5 \mathrm{~cm} \times 6-10 \mathrm{~mm}$ de diámetro.

Se distribuye desde México hasta Sudamérica. En México se conoce de Aguascalientes, Baja California, Baja California Sur, Campeche, Chiapas, Chihuahua, Colima, D.F., Durango, Guerrero, Hidalgo, Jalisco, México, Michoacán, Morelos, Nayarit, Oaxaca, Puebla, Querétaro, Quintana Roo, San Luis Potosí, Sinaloa, Sonora, Tabasco, Tamaulipas, Veracruz, Yucatán y Zacatecas (Diego-Pérez, 2004; Juárez-Jaimes et al., 2007). En Morelos se ha colectado en Amacuzac, Coatlán del Río, Cuautla, Cuernavaca, Emiliano Zapata, Jiutepec, Jojutla, Puente de Ixtla, Tepalcingo, Tepoztlán, Tlaquiltenango, Tlayacapan, Xochitepec, Yautepec y Zacatepec. Fig. 5.

Especie típica del estrato arbóreo del bosque tropical caducifolio en la entidad, se encuentra en altitudes de 840 a $1900 \mathrm{~m}$. Florece de febrero a octubre y fructifica en agosto y septiembre. En el estado, es una planta cultivada ampliamente por sus flores vistosas y aromáticas, asimismo tiene una importancia ceremonial, ya que en algunas poblaciones en el municipio de Tlayacapan se utiliza para decorar imágenes religiosas y el látex se emplea en la medicina tradicional.

Ejemplares examinados. Amacuzac. Al poniente de Zoquital, 18³1'31.6" N, 99 22'15.2" W, Betancourt 58 (HUMO). Coatlán del Río. Sin localidad, 6 oct 1975, Torres s.n. (FCME); Torres 96 (MEXU). Cuautla. Sin localidad, 26 may 1974, Palacios s.n. (ENCB). Cuernavaca. Alrededores de la Universidad de Cuernavaca, 19 jun 1976, Acevedo s.n. (FCME); antigua corriente de lava en la carretera Cuernavaca - Tepoztlán, Miranda 1288 (MEXU); campos de lava cerca de Cuernavaca, Pringle 6866 (ENCB, MEXU). Emiliano Zapata. NE de Tepetzingo, Bastida 991 (MORE). Jiutepec. Texcal Tejalpa km 7 carr. Tepoztlán, Vázquez 1884 (MEXU). Jojutla. Sin localidad, 17 feb 1955, Becerra s.n. (MEXU); cerro del Higuerón, 2 km del centro del mpio., cuesta E, 18³5'20.8" N, 99 9'10.4" W, Raz et al. 148 (HUMO); cerro del Higuerón, en la ladera NW, Rivera 127 (MEXU). Puente de Ixtla. Tilzapotla, $1.5 \mathrm{~km}$ al NW, al W de la presa Emiliano Zapata, 18³6'35.31" N, 99²1'37.05" W, Bonfil 25 (MEXU, UAMIZ); a 2-3 km al W de Coaxitlán una brecha a la derecha, 18²6'42.4" N, 99¹2'36.7" W, Bustamante et al. 177 (HUMO); en la comunidad del Zapote, $18^{\circ} 28^{\prime} 05^{\prime \prime} \mathrm{N}, 9^{\circ} 19^{\prime} 34^{\prime \prime} \mathrm{W}$, González-Rocha et al. 1 (UAMIZ); cultivada en casa particular, en la comunidad El Zapote, 18²8'11" N, 99¹9'41" W, González-Rocha et al. 2 (UAMIZ); $3 \mathrm{~km}$ antes El Zapote, 18²8'20" N, 99²0'52" W, González-Rocha et al. 4 (UAMIZ); a 4 km al SW de Coaxitlán, 18²5'15.4" N, 99¹1'37.4" W, Juárez et al. 975 (HUMO). Tepalcingo. En el Mogote del cerro Prieto - Momoxtles, al S del po- 
blado El Limón, 18²9'28.9" N, 9857'27.8" W, Almonte 207 (HUMO); a 3 km al N de El Limón, cañada Los Sabinos, Bonilla-Barbosa 1468 (FCME, HUMO, MEXU); $2.5 \mathrm{~km}$ al E de El Limón, 18³2'0" N, 98 54'49" W, Juárez et al. 383b (HUMO); camino los Sauces El Limón, Martínez y Dorado 3314 (UAMIZ), Arias 2242 (MORE), Monroy 3314 (MORE); $3 \mathrm{~km}$ al SW de El Limón de Cuahuchichinola 18³0'19" N, 9857'14" W, Ramírez 119, 120 (HUMO). Tepoztlán. Santo Domingo, Vega 2326 (MORE); Santa Catarina, entrada a la parroquia de 3 de Mayo, 8 may 1987, Beltrán s.n. (HUMO); camino al cerro Tepozteco, García 23 (ENCB); carretera a Tepoztlán ( $k m$ 7), Vázquez 1884 (MEXU). Tlaquiltenango. En el cerro de La Laguna, en la comunidad de Quilamula, 18³7'28.3" N, 999'30" W, Aragón 76 (HUMO); a 3.5 km al SE de Coaxitlán, 18²6'20.8" N, 99¹0'25.1" W, Betancourt 148 (HUMO); a 7 km al NW de Huautla, 18²8'59.7" N, 990'26.7" W, Castro y Villegas 1127(HUMO); a 5 $\mathrm{km}$ al oriente de Huautla, 18²6'57.7" N, 9859'42.8" W, Castro et al. 884 (HUMO); $2 \mathrm{~km}$ al N de Xochipala, Castro y Mazón 999 (HUMO); $7 \mathrm{~km}$ al oriente de Ajuchi-

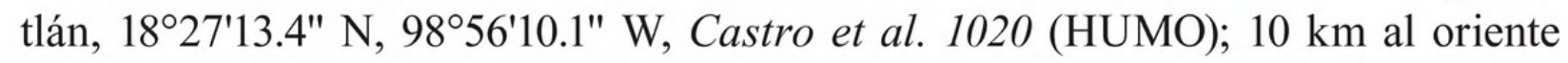
de Ajuchitlán, 18²7'11.3" N, 9855'22.9" W, Castro et al. 1029 (FCME, HUMO); a $2 \mathrm{~km}$ al poniente de Huautla, Castro y Villegas 1045 (HUMO); $0.75 \mathrm{~km}$ al SW de Huaxtla, 18²2'18" N, 99²'56" W, Cerros et al. 456 (HUMO, MEXU); $3 \mathrm{~km}$ al NW de Huautla,18²7'14" N, 99²'33" W, Cerros et al. 541 (HUMO); 3.5 km al SE de Ajuchitlán, 18²7'27" N, 9856'32" W, Cerros et al. 694 (HUMO); 1 km al N de Xochipala, 18²6'31" N, 9858'22" W, Cerros et al. 1042 (HUMO); $2.25 \mathrm{~km}$ de Xochipala, 18²4'50" N, 994'15" W, Cerros et al. 1090 (HUMO); camino que va al Perillo, $1.25 \mathrm{~km}$ al W de Huaxtla, 18²2'35" N, 99³'4" W, González-Rocha et al. 16 (UAMIZ); $1.7 \mathrm{~km}$ al S de Huaxtla, 18²1'29.8" N, 99³'10.6" W, González-Rocha et

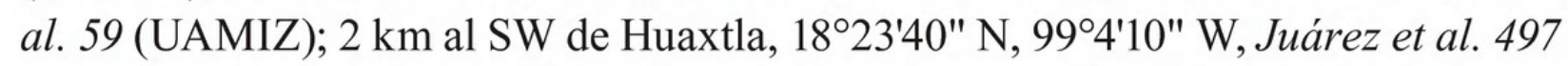
(HUMO, MEXU); a $3 \mathrm{~km}$ de Rancho Viejo, 18²5'3.9" N, 990'11.5" W, Juárez et al. 881 (HUMO); a $3.3 \mathrm{~km}$ de Xantiopan, 18²5'16.9" N, 98²5'32.3" W, Juárez et al. 891 (HUMO); a $4 \mathrm{~km}$ al W de Xantiopan, 18²5'20.7" N, 9858'15.8" W, Juárez et al. 893 (HUMO); 4-5 km al E de El Limón, 18³1'49.3" N, 9854'18.8" W, Juárez et al. 901 (HUMO); Nexpa, a 10 km del Higuerón - Jojutla, 18³7'23.86" N, 99¹1'0.06" W, Lorenzana 5 (UAMIZ); 1 km al S de Chimalacatlán, Maldonado 1175 (HUMO); $4.5 \mathrm{~km}$ al N de Huautla, 18²8'49" N, 99¹'40" W, Ramírez et. al 251 (HUMO); $1 \mathrm{~km}$ al W de Huaxtla, 18²2'54" N, 99³'13" W, Ramirez et al. 647 (HUMO); $2.5 \mathrm{~km}$ al SW de Ajuchitlán, 18²7'45" N, 990'1" W, Ramírez et al. 1553 (HUMO); $1 \mathrm{~km}$ al S de Chimalacatlán, 18²7'20" N, 99 5'55" W, Ramírez et al. 1448 (HUMO); Huautla, $18^{\circ} 27^{\prime} 00^{\prime \prime} \mathrm{N}, 9^{\circ} 01^{\prime} 10^{\prime \prime} \mathrm{W}$, Wilke 28 (HUMO). Tlayacapan. Al S de la barranca Tepecapa, a $1.9 \mathrm{~km}$ al SW de San José de Los Laureles, $18^{\circ} 57^{\prime} 42.2^{\prime \prime}$ N, 990'41.7" 
W, Hernández-Cárdenas et al. 363 (UAMIZ); a $1.5 \mathrm{~km}$ de la capilla del Tránsito, colonia El Plan, cerro El sombrerito, ladera S, 1856' $8^{\prime \prime}$ N, 9859'3" W, Serrano 41 (HUMO, UAMIZ). Xochitepec. Sin localidad, 13 abr 1912, Salazar s.n. (MEXU). Yautepec. Cañón de lobos, Germán 452 (MEXU). Zacatepec. Sin localidad, 31 jul 1965, Palacios s.n. (ENCB).

PRESTONIA R. Br., Asclepiadeae 58. 1810.

Lianas sufrutecentes con látex transparente; tallos teretes, híspidos con pelos amarillos, coléteres intrapeciolares conspicuos. Hojas opuestas, pecioladas, sin coléteres en la lámina, láminas pubescentes, membranáceas. Inflorescencia cimosa, axilar; brácteas florales foliáceas; cáliz con sépalos iguales, foliáceos, pubescentes, con un coléter en la base de la cara adaxial; corola hipocrateriforme, amarilla, con una corona anular alrededor de la garganta, 5 lóbulos coronales ausentes, reducidos a crestas callosas lineares, prefloración dextrocontorta, tubo recto; estambres incluidos, anteras conniventes y unidas a la cabeza estigmática, sin apéndices supra e infraestaminales; cabeza estigmática fusiforme, con un anillo basal; gineceo apocárpico, bicarpelar, ovario súpero, con un nectario, 5-lobado. Frutos en folículos, apocárpicos, divaricados, hirsutos; semillas truncadas y comosas en el ápice micropilar.

Género con 55 especies, distribuido desde México hasta Argentina (excepto Chile y Uruguay) y las Antillas. En México existen cuatro taxa, de las cuales uno se conoce de Morelos.

Prestonia mexicana A. DC., Prodr. 8: 429. 1844. Mitozus mexicanus (A. DC.) Miers, Apocyn. S. Am. 225. 1878. Tipo: México, Oaxaca, San Bartolo, Andrieux 251 (Holotipo: G, foto ENCB). Fig. 4B.

Echites conglobatus Sessé \& Moc., Naturaleza (Mexico City), ser. 2, 2 app.: 45. 1893. Tipo: México, Sessé et al. 5082 (Holotipo: MA, fragmento en F).

Lianas de 3-6 m de altura; tallos teretes, híspidos con pelos amarillos, con coléteres interpeciolares de $2 \mathrm{~mm}$ de largo. Hojas opuestas, láminas anchamente ovadas a obovadas, de 8-27 cm de largo $\times 5-16 \mathrm{~cm}$ de ancho, ápice acuminado, base redondeada a subcordada, haz piloso, envés densamente tomentoso o tomentuloso, con marcada venación secundaria en ambas superficies, membranáceas, peciolos de $0.5-2 \mathrm{~cm}$ de largo, tomentosos. Inflorescencia una cima axilar de hasta 30 flores, pedúnculo de 0.9-4.4 $\mathrm{cm}$ de largo, tomentoso, pedicelo de 0.5-3.2 cm de largo, to- 
mentoso; brácteas florales verdes, lanceoladas, de 0.5-3.2 cm de largo $\times 1-3.5 \mathrm{~mm}$ de ancho, tomentulosas; cáliz con 5 sépalos verdes, lanceolados a oblongos, de 1.4-3 cm de largo $\times$ 4-12 mm de ancho, tomentosos; corola hipocrateriforme, amarilla, tomentosa, tubo de 2.4-3.6 cm de largo $\times$ 4-5 $\mathrm{mm}$ de ancho, lóbulos coronales ausentes o reducidos a crestas, corona anular entera, lóbulos obovados, de 12-16 mm de largo $\times$ 9-11 mm de ancho, redondeados, recurvados; estambres incluidos, filamentos libres, de 1.7-2 mm de largo, anteras de 6-7 mm de largo, fusionados a la cabeza estigmática; cabeza estigmática de 1-1.5 mm de largo, ovario de 1-1.5 mm de largo, nectarios concrescentes de $1.5 \mathrm{~mm}$ de largo. Folículos verdes, de apariencia amarilla por el indumento, fusiformes, divaricados, de $5.5-11 \mathrm{~cm}$ de largo de diámetro, ferrugíneos; semillas comosas, pardas, de 11-15 $\mathrm{mm}$ de largo $\times 2-3 \mathrm{~mm}$ de ancho, coma amarillo, de 2.5-4.2 $\mathrm{cm}$ de largo.

Especie que se distribuye de México a norte de Sudamérica (en Belice, Colombia, Costa Rica, El Salvador, Guatemala, Honduras, Nicaragua y Panamá). También en Australia y China. En México se conoce de Campeche, Chiapas, Colima, Guanajuato, Guerrero, Jalisco, Michoacán, Morelos, Nayarit, Oaxaca, Querétaro, Quintana Roo, San Luis Potosí, Tabasco y Veracruz (Juárez-Jaimes et al., 2007). En Morelos P. mexicana se encuentra en el bosque tropical caducifolio en los municipios de Cuernavaca, Puente de Ixtla y Tepalcingo, en altitudes entre 1100 y $1550 \mathrm{~m}$. Fig. 5.

Esta especie solo se había reportado de los municipios de Cuernavaca y Tepalcingo, pero en este estudio se recolectaron especímenes en el de Puente de Ixtla y con ello se amplía su distribución conocida. La floración se registra en junio y julio y la fructificación en noviembre. Calderón de Rzedowski y Rzedowski (1998) sugieren que la planta es vulnerable a la extinción debido a su escasez de individuos, sin embargo esto podría deberse al efecto de muestreo y es probable que en los próximos años se revele su presencia en otros municipios.

Ejemplares examinados: Cuernavaca. Barranca cerca de Cuernavaca, Pringle 6224 (MEXU), Pringle 6341 (ENCB, MEXU). Puente de Ixtla. Camino al Zapote, a $50 \mathrm{~m}$ en la subida al Mango, 18²9'14.2" N, 99²0'38.2" W, González-Rocha et al. 78 (UAMIZ). Tepalcingo. Camino Los Sauces - El Limón, Arias y Dorado 3332 (MORE), ibid., Soria y Monroy 3332 (MORE).

RAUVOLFIA L., Sp. Pl. 1: 208. 1753.

Árboles o arbustos, con látex blanco; tallos angulados a subcilíndricos o cilíndricos, pubescentes o glabros, con coléteres intrapeciolares diminutos e inconspi- 
cuos. Hojas verticiladas, anisófilas en el mismo nudo, cortamente pecioladas o sésiles, con coléteres a lo largo del peciolo, sin coléteres en las láminas, láminas glabras a pubescentes, membranosas. Inflorescencia cimosa, axilar o terminal; brácteas florales escuamiformes; cáliz con sépalos iguales, foliáceos, glabros o pubescentes, sin coléteres en la base de la cara adaxial; corola hipocrateriforme o infundibuliforme, blanca, de color crema, verde o rosada, urceolada o campanulada, sin corona anular, sin lóbulos coronales libres, prefloración sinistrocontorta, tubo floral sin crestas supra o infraestaminales, urceolado; estambres incluidos, anteras no conniventes ni aglutinadas a la cabeza estigmática, sin apéndices supra e infraestaminales; cabeza estigmática más o menos cilíndrica, no lobulada en la base; gineceo sincárpico, bicarpelar, ovario súpero, con un nectario anular, entero o lobulado. Fruto una drupa, sincárpicas, con el exocarpo carnoso, rojo cuando joven, morado al madurar, glabras; semillas desnudas, glabras, no comosas.

Género pantropical con cerca de 100 especies (Koch, 2002). En México se conocen dos, de las cuales una en Morelos.

Rauvolfia tetraphylla L., Sp. Pl. 1: 208. 1753. Tipo: Herb. Clifford 75, Rauvolfia No. 1. (Lectotipo) designado por Leeuwenberg, Regnum Veg. 127: 81. 1993 (BM). Fig. 4C.

Rauvolfia canescens L., Sp. pl. ed. 2: 303. 1762. Tipo: Tipo: Burman, J. (ed.). 1776. Plantarum americanarum fasciculus primus-decimus. Fasc. 10:t. 236, f. 2

Rauvolfia heterophylla Willd. ex Roem. \& Schult., Syst. Veg. 4: 805. 1819. Tipo: Sin localidad precisa, Humboldt \& Bonpland s.n. (Holotipo: B-Willd).

Rauvolfia canescens var. tomentosa Müll. Arg., Linnaea 30: 396. 1860. Tipo: St. Martham, Goudot 2 (Holotipo: G).

Rauvolfia latifolia var. minor Müll. Arg., Linnaea 30: 396. 1860. pro parte. Tipo: in insula Trinitatis, Sieber 268 (Sintipo: W!; Isosintipos: G!, MO!).

Rauvolfia odontophora Heurck \& Müll. Arg. In Heurck, Obs. Bot.: 150. 1870. Tipo: Ecuador, Guayas, Guayaquil, Spruce 6302 (Holotipo: W; Isotipos: NY, P, S).

Rauvolfia mollissima Markgr., Repert. Spec. Nov. Regni Veg. 20: 119. 1924. Tipo: Costa Rica: Guanacaste: bosques de Nicoya, Mai 1900 (fl.), Tonduz 13940 (Lectotipo: US, foto INB) designado por Morales, Darwiniana 43: 158. 2005).

Arbustos de 1-1.5 m de altura; tallos cilíndricos, glabros, los coléteres intrapeciolares de ca. $1 \mathrm{~mm}$ de largo. Hojas verticiladas, anisófilas, láminas obovadooblanceoladas a elípticas, las más largas de $5-11 \mathrm{~cm}$ de largo $\times 1.2-3.5 \mathrm{~cm}$ de ancho, las más cortas de $1.5-4 \mathrm{~cm}$ de largo $\times 0.5-2 \mathrm{~cm}$ de ancho, ápice apiculado, base 
aguda, generalmente glabras por ambos lados, con marcada venación secundaria en ambas superficies, membranáceas a cartáceas, peciolos de 1-6 mm de largo, glabros a esparcidamente puberulentos, con coléteres a lo largo del peciolo, de ca. $1 \mathrm{~mm}$ de largo. Inflorescencia una cima axilar o terminal, de 2 a 9 flores, pedúnculo de 5-16 $\mathrm{mm}$ de largo, esparcidamente puberulento, pedicelo de 2-5 $\mathrm{mm}$ de largo, puberulento o glabro; brácteas florales verdes, ovadas, de ca. 1-1.5 mm de largo $\times 0.5-0.7 \mathrm{~mm}$ de ancho, puberulentas; cáliz con 5 sépalos verdes, ovados, de $1-2 \mathrm{~mm}$ de largo $\times$ 1-1.5 mm de ancho, puberulentos; corola urceolada, blanca o blanco-verdosa, tubo de 2-2.5 mm de largo $\times 1.5-2 \mathrm{~mm}$ de diámetro, lóbulos obovados, de 0.6-1.5 mm de largo $\times$ 0.7-1 mm ancho, redondeados, erectos; estambres incluidos, filamentos libres, de menos de $1 \mathrm{~mm}$ de largo, anteras de $1 \mathrm{~mm}$ de largo, libres de la cabeza estigmática; cabeza estigmática de ca. $1 \mathrm{~mm}$ de largo, estilo de 1.5-2 mm de largo; ovario de ca. $1 \mathrm{~mm}$ de largo, rodeado de un nectario entero, de ca. $1 \mathrm{~mm}$ de largo. Drupas rojas, moradas al madurar, globosas, de $0.5-1 \mathrm{~cm}$ de largo $\times 0.7-1 \mathrm{~cm}$ de diámetro, glabras; semillas 1 o 2, de 3-5 mm de largo, con la testa membranácea.

Especie con distribución en México, Mesoamérica, Colombia, Venezuela, Ecuador, Perú y Antillas. En México se conoce de Campeche, Chiapas, Colima, Guanajuato, Guerrero, Jalisco, México, Michoacán, Morelos, Nayarit, Oaxaca, Puebla, Querétaro, Quintana Roo, San Luis Potosí, Sinaloa, Tabasco, Tamaulipas, Veracruz y Yucatán (Juárez-Jaimes et al., 2007). En Morelos se ha colectado en Coatlán del Río, Jiutepec, Mazatepec, Miacatlán, Puente de Ixtla, Tlaquiltenango, Xochitepec y Yautepec. Fig. 5.

Esta especie se encuentra en bosque tropical caducifolio y en bosque de galería, en altitudes de 800 a $1700 \mathrm{~m}$. Se ha colectado en flor entre abril y mayo y en fruto entre junio y enero.

Ejemplares examinados. Coatlán del Río. Ribera del Río Coatlán, cerca de Coatlán del Río, 27 ago 1967, Flores-Crespo s.n. (ENCB); camino hacia El Hoyanco, 18 44'5.61" N, 99 26'02" W, González-Rocha et al. 58 (UAMIZ); a orilla del canal, hacia El Hoyanco, 1844'8.2" N, 99²6'00" W, Miguel-Vázquez et al. 71 (UAMIZ); barranca de la derecha de las grutas de Cacahuamilpa, Miranda 440 (MEXU). Jiutepec. Puente de Xóchitl km 91-92 carretera Acapulco, Vázquez 363 (MEXU). Mazatepec. Iglesia de Mazatepec, González-Rocha et al. 83 (UAMIZ). Miacatlán. Miacatlán, camino al antiguo trapiche, Reyes 1340 (UAMIZ). Puente de Ixtla. Cañada de Ahuetzingo, 18³9'09.26" N, 99²0'50.6" W, Navarro 20 (FCME). Tlaquiltenango. $4 \mathrm{~km}$ al S de Coaxitlán, $18^{\circ} 24^{\prime} 55.3^{\prime \prime} \mathrm{N}, 99^{\circ} 10^{\prime} 37.0^{\prime \prime} \mathrm{W}$, Betancourt 11 (HUMO); $0.5 \mathrm{~km}$ al N de Rancho Viejo, 18 $25^{\prime} 45^{\prime \prime} \mathrm{N}, 9^{\circ} 0^{\prime} 50^{\prime \prime} \mathrm{W}$, Castro 85 (HUMO); $1 \mathrm{~km}$ al S de Huautla, 18²6'0" N, 99¹'5" W, Castro 449 (HUMO); 5 km 


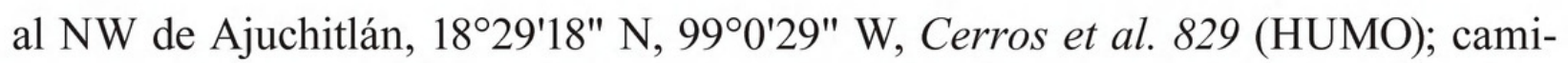
no al río al S de Huaxtla, 18²2'46.1" N, 9902'44.9" W, González-Rocha et al. 82 (UAMIZ); Joya del Agua Brava, km 119 carretera Ixtapan - Taxco, Vázquez 2318b (MEXU). Xochitepec. Sin localidad, 16 jul 1938, Lyonnet 2185 (ENCB, FCME); Palo Bolero, en la orilla de la carretera, Vázquez 1166, 2318 a (MEXU). Yautepec. Oaxtepec, Gallegos 326 (MEXU).

TABERNAEMONTANA L., Sp. Pl. 1: 210-211. 1753.

Arbustos o árboles, con látex blanco; tallos subcilíndricos, glabros a puberulentos, con coléteres interpeciolares diminutos e inconspicuos. Hojas opuestas, pecioladas, sin coléteres en la lámina, láminas glabras o pubescentes, membranáceas o coriáceas. Inflorescencia cimosa, axilar o terminal; brácteas florales foliáceas; cáliz con sépalos iguales o desiguales, foliáceos, glabros o puberulentos, con numerosos coléteres dispuestos en la base de la cara adaxial, a veces rodeado por bractéolas dispuestas en forma irregular o sobre el pedicelo; corola hipocrateriforme o infundibuliforme, amarilla, amarillo-verdosa o blanca, sin corona anular, sin lóbulos coronales libres, prefloración sinistrocontorta, tubo floral con o sin 5 crestas supra e infraestaminales, recto o a veces con torsiones en espiral donde se encuentran los estambres; estambres incluidos, anteras no conniventes ni aglutinadas a la cabeza estigmática, sin apéndices supra e infraestaminales; cabeza estigmática subglobosa con un collar basal o fusiforme, no lobulada en la base; gineceo apocárpico, bicarpelar, ovario súpero, con un nectario concrescente o ausente. Frutos en folículos, apocárpicos, elipsoidales o reniformes, carnosos; semillas desnudas, no comosas, rodeadas por un arilo rojo o anaranjado.

Género con aproximadamente 117 especies que se distribuyen en los trópicos de África, Asia, islas del Pacífico y América (desde México hasta Argentina y las Antillas). En México se conocen 12 especies, dos de las cuales se han colectado en Morelos. Tradicionalmente Stemmadenia Benth. y Tabernaemontana se han visto envueltos en una controversia taxonómica en el sentido de reconocerlos como una o dos entidades. Por ejemplo, Woodson (1928) separó ambos géneros por la presencia de bractéolas debajo del cáliz o el número de coléteres en los sépalos. Morales y Méndez (2005) señalaron que dichos caracteres no eran constantes y que solo las crestas o las alas infra o supraestaminales permitía diferenciarlos. Sin embargo, Simões et al. (2010) destacaron que en el pasado se han señalado mas sus diferencias que sus similitudes. Asimismo, evaluaron los límites genéricos apoyados en un análisis filogenético basados en evidencia molecular de la tribu Tabernamontaneae 
s.l. sugiriendo la inclusión de Stemmadenia en Tabernamontana y proporcionando cambios nomenclaturales de las especies de Stemmadenia. En este estudio se sigue tal propuesta.

Clave para la determinación de especies de Tabernaemontana

1 Hojas con el haz pubescente; sépalos desiguales, de 1.5-2.5 cm de largo; folículos sin costillas laterales evidentes T. odontadeniiflora

1 Hojas con el haz glabro; sépalos iguales, de $0.25-0.63 \mathrm{~cm}$ de largo; folículos con dos costillas laterales evidentes

T. tomentosa

Tabernaemontana odontadeniiflora A. O. Simões \& M. E. Endress, Taxon 59(3): 787. 2010. Fig. 4D. Stemmadenia pubescens Benth., Bot. Voy. Sulphur 125. 1845. Bignonia (?) obovata Hook. \& Arn., Bot. Beechey Voy.: 439. 1841., nom. illeg., non Spreng., (1825). Stemmadenia obovata K. Schum., in Engler \& Prantl., Nat. Pflanzenfam. 4(2): 149. 1895, nom. illeg. Tipo: México, San Luis Potosí, Realejo, Sinclair s.n. (Holotipo: K).

Stemmadenia mollis Benth., Bot. Voy. Sulphur 125. 1845. Stemmadenia obovata var. mollis (Benth.) Woodson, Ann. Missouri Bot. Gard. 15(4): 358. 1928. Tipo: Ecuador, Guayaquil, Guayanas, Sinclair s.n. (Holotipo: K).

Stemmadenia calycina Brandegee, Univ. Calif. Publ. Bot. 10(2): 188. 1922. Tipo: México, Veracruz, Remulatero, Purpus 8771 (Holotipo: UC).

Nombres comunes registrados en la zona: chiclillo, chiclio, tepechicle.

Árboles o arbustos de 1-6 m de altura; tallos subcilíndricos, glabros, con coléteres intrapeciolares de ca. $1 \mathrm{~mm}$ de largo. Hojas opuestas, láminas obovadoelípticas, de 10-19 cm de largo $\times 5-10 \mathrm{~cm}$ de ancho, ápice acuminado, mucronado o retuso en las hojas jóvenes, base cuneada, haz pubescente, piloso por el envés en la vena principal y media, con marcada venación secundaria en ambas superficies, peciolos de 3.5-7.7 $\mathrm{mm}$ de largo, pilosos. Inflorescencia una cima axilar de 1 a 4 flores, pedúnculo de 1-1.7 $\mathrm{cm}$ de largo, puberulento, pedicelo de 7-11 $\mathrm{mm}$ de largo, pubescente; brácteas florales escariosas, ovadas, de 1.5-4 mm de largo $\times 1.5-3 \mathrm{~mm}$ de ancho, pubescentes; cáliz con 5 sépalos oblongo-elípticos, desiguales, de 1.5-2.5 $\mathrm{cm}$ de largo $\times$ 0.3-0.7 cm de ancho, puberulentos, con más de 30 coléteres dispuestos en 2 series, sépalos generalmente acompañados de 2 bracteolas ovadas de $4-13 \mathrm{~mm}$ de largo $\times 3.5-8.5 \mathrm{~mm}$ de ancho, puberulentas; corola infundibuliforme, amarilla, 
con crestas supra e infraestaminal, parte inferior del tubo de 1.6-2.5 cm de largo $\times$ 4-5 $\mathrm{mm}$ de diámetro, éste contorneado alrededor de los estambres, parte superior campanulada, de 1-1.5 cm de largo, diámetro de la garganta de 1.7-2.5 cm, lóbulos obovados, de 2.5-3 cm de largo $\times 2.4-2.7 \mathrm{~cm}$ de ancho, redondeados, revolutos; estambres incluidos, filamentos libres, anteras de ca. $4-5 \mathrm{~mm}$ de largo, libres de la cabeza estigmática; cabeza estigmática de 1-2 $\mathrm{mm}$ de largo, estilo de $1-1.5 \mathrm{~cm}$ de largo, ovario de ca. $2 \mathrm{~mm}$ de largo, rodeado de un nectario anular de ca. $1 \mathrm{~mm}$ de largo. Folículos verdes cuando jóvenes, pardos al madurar, elipsoidales a reniformes, con el ápice largamente acuminado, sin costillas laterales evidentes, de 4.8-5.5 cm de largo $\times 2.6-4.5 \mathrm{~cm}$ de diámetro, glabros; semillas numerosas, de $6.5-13 \mathrm{~mm}$ de largo $\times$ 3-5 $\mathrm{mm}$ de ancho, con arilo de color anaranjado.

Se distribuye en México, Belice, Costa Rica, El Salvador, Guatemala, Honduras, Nicaragua, Panamá, Bolivia, Colombia, Venezuela, Ecuador y Perú. En México se conoce de Chiapas, Chihuahua, Durango, Guerrero, Jalisco, México, Michoacán, Morelos, Nayarit, Oaxaca, Puebla y Veracruz (Juárez-Jaimes et al., 2007). En Morelos se registra de los municipios de Amacuzac, Ayala, Coatlán del Río, Cuernavaca, Emiliano Zapata, Jiutepec, Jojutla, Jonacatepec, Miacatlán, Puente de Ixtla, Tlaltizapan, Tlaquiltenango, Xochitepec, Yautepec y Zacatepec. Fig. 5.

Es una especie muy abundante en el sur del estado y es típica del bosque tropical caducifolio, en altitudes de 720 a $1600 \mathrm{~m}$. Florece de febrero a noviembre y fructifica en julio y diciembre. Tabernaemontana odontadeniiflora muestra una gran variabilidad en cuanto al indumento de las hojas y frecuentemente se le ha identificado como T. tomentosa. Sin embargo, los individuos de T. odontadeniiflora se diferencian por tener sépalos desiguales, incluso llegando a igualar el largo del tubo inferior de la corola, mientras que en T. tomentosa los sépalos son del mismo tamaño y llegan a medir hasta $6 \mathrm{~mm}$ de largo.

Ejemplares examinados. Amacuzac. $1.2 \mathrm{~km}$ al S de Rancho Viejo, $18^{\circ} 33^{\prime} 55.7^{\prime \prime}$ N, 99²2'55" W, Betancourt y Brito 38 (HUMO); SE de Miahuatlán, Monroy 6557 (MORE); Cazahuatlán, Monroy 6585 (MORE). Ayala. Moyotepec, $3 \mathrm{~km}$ al S de Las Piedras, Lott 296 (ENCB). Coatlán del Río. Apancingo, Soria 7754 (MORE). Cuernavaca. $8 \mathrm{~km}$ al S de Cuernavaca, González 2613 (ENCB); km 94 entre Cuernavaca y Alpuyeca, sin colector 3510 (MEXU). Emiliano Zapata. $3.5 \mathrm{~km}$ al SE de Temimilcingo, Monroy 769 (MORE). Jiutepec. Entre la colonia A. Salazar y el Cañón de Lobos, Monroy 2188 (MORE); Puente de Xóchitl, km 91-92 de la carretera federal Acapulco, Vázquez 365 (MEXU); Lago Ahueyapan - Tejalpa, Medina 93 (UAMIZ). Jojutla. Lago de Tequesquitengo, Alpuyeca, Atmar 31 (MEXU). Jonacatepec. $2 \mathrm{~km}$ al S de Tlayca, 1842'0" N, 9850'9" W, G. Flores 299 (MEXU). 
Miacatlán. $3 \mathrm{~km}$ delante de las ruinas de Chalcatzingo, Monroy 3883 (MORE). Puente de Ixtla. $3 \mathrm{~km}$ carretera al $\mathrm{W}$ de la presa, Almonte 4 (HUMO); Tilzapotla, $1.5 \mathrm{~km}$ al N, lado E de la presa E. Zapata, Bonfil 7 (UAMIZ); 2-3 km antes de Coaxitlán, Bustamante 148 (HUMO); 2-3 km al W de Coaxitlán una brecha a la derecha, Bustamante 167 (HUMO); 3 km al W rumbo a Coaxitlán, $18^{\circ} 26^{\prime} 40.8^{\prime \prime} \mathrm{N}, 9^{\circ} 13^{\prime} 30^{\prime \prime}$ W, Bustamante 194 (HUMO); a $200 \mathrm{~m}$ del Comal, sobre carretera de terracería, 18²9'36.2" N, 99¹9'13.7" W, Bustamante 634 (HUMO); SE de Tilzapotla, Castillo et al. 6652 (MEXU, MORE, UAMIZ); sobre el río Tilzapotla, Castillo et al. 6763 (MORE); camino al Zapote, $5 \mathrm{~km}$ antes del Zapote, 18²8'35.04" N, 99²0'29.88" W, González-Rocha et al. 8 (UAMIZ); $4.5 \mathrm{~km}$ antes del Zapote, 18²9'11.17" N, 99²0'36.1" W, González-Rocha et al. 9 (UAMIZ); $1 \mathrm{~km}$ abajo del entronque al Mango, 18²9'56" N, 99¹9'50" W, González-Rocha et al. 11 (UAMIZ); a 500 m de Los Tanques, 18³0'19" N, 99¹8'54" W, González-Rocha et al. 12 (UAMIZ); camino al Zapote, a $1 \mathrm{~km}$ de la Virgen, 18²9'34.4" N, 99²0'25.6" W, González-Rocha et al. 81 (UAMIZ); $1 \mathrm{~km}$ al SE de la tercera a la salida de Tilzapotla, $18^{\circ} 28^{\prime} 39.5^{\prime \prime} \mathrm{N}, 9^{\circ} 14^{\prime} 53.6^{\prime \prime} \mathrm{W}$, Juárez et al. 997 (HUMO); $1 \mathrm{~km}$ al S de Tilzapotla, 18²8'14.9" N, 99¹6'5.2" W, Juárez et al. 1037 (HUMO); Tilzapotla, camino de terracería Tilzapotla - Coaxintlán, a $3 \mathrm{~km}$ saliendo de Tilzapotla, 18²7'35.2" N, 99'13'22.6" W, Juárez et al. 1090 (HUMO); a 250 m al E de Tilzapotla, 18²9'16.4" N, 99¹5'49.5" W, Juárez et al. 1155 (HUMO); cañada de Ahuehuesingo, Navarro 18 (FCME); Tilzapotla, Quezada 1610 (MEXU); a $5 \mathrm{~km}$ sobre carretera hacia El

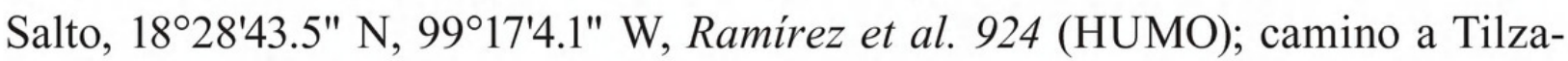
potla, 18²9'37.2" N, 99¹8'5.4" W, Ramírez 947 (HUMO). Tlaltizapan. Cerca de la cueva de El Salitre, Tetecalita, Ortiz 571 (MEXU); Las estacas (orillas camino), Vázquez 1168 (MEXU); Temimilcingo en el monte entre la vía y las huertas, Vázquez 1440 (MEXU). Tlaquiltenango. $40 \mathrm{~m}$ al poniente de la presa en el poblado de Ajuchitlán, Almonte 1565 (HUMO); cerca de la barranca de Agua Salada en la comunidad de Huixastla, Aragón 9 (HUMO); 4 km al S de Coaxtitlán, 18²4'55.3" N, 99¹0'37" W, Betancourt 115 (FCME, HUMO); 1 km al S de Valle de Vázquez, carretera a Chimalacatlán, 7 oct 1988, Castillo s.n. (HUMO, MEXU); $2 \mathrm{~km}$ al oriente de Huaxtla, 18²3'3.1" N, 99²'22" W, Castro 808 y Mazón (HUMO); 2 km al poniente de Ajuchitlán, 18²8'7.5" N, 98 59'20.5" W, Castro et al. 934 (HUMO); 6-7 km al S de Rancho Viejo, 18²7'44.7" N, 98 59'20" W, Castro y Mazón 940 (HUMO); 1 km S de Rancho Viejo, 18²4'56.1" N, 9940'45" W, Castro y Mazón 975 (HUMO); $2.5 \mathrm{~km}$ al poniente de Huautla, 18²4'51.1" N, 98 58'10.6" W, Castro y Villegas 1047 (HUMO); 7 km al NW de Huautla, 18²8'43.6" N, 9859'55.2" W, Castro y Villegas 1139 (HUMO); $2 \mathrm{~km}$ al oriente de Ajuchitlán, 18²8'4.8" 
N, 9857'40.7" W, Castro y Villegas 1187 (HUMO); 4-5 km NW de Ajuchitlán, $18^{\circ} 28^{\prime} 51.9^{\prime \prime} \mathrm{N}, 9^{\circ} 57^{\prime} 40.7^{\prime \prime} \mathrm{W}$, Castro y Villegas 1203 (HUMO); $3 \mathrm{~km}$ al N de Huaxtla, Cerros et al. 505 (HUMO, MEXU); 1 km de Xochipala, 18²6'31" N, 98 $58^{\prime} 22^{\prime \prime}$ W, Cerros 1031 (FCME, HUMO); 1 km de Xochipala 18²5'13" N, 99³'36" W, Cerros 1075 (FCME, HUMO); 7.5 km al NW de Ajuchitlán, 18²8'1" N, 9858'59" W, Cerros 1200 (HUMO); 1 km al S de Valle de Vázquez, 18³0'44.52" N, 994'52.64" W, Espin 2 (HUMO, UAMIZ); $1.75 \mathrm{~km}$ al NW de Huautla, 18²7'5" N, 99 $1^{\circ} 50^{\prime \prime}$ W, Flores-Castorena 1369 (HUMO); Huaxtla, orilla del Río Amacuzac, a $5.5 \mathrm{~km}$ al W de Huaxtla en el camino que va al Perillo, 18²2'34" N, 99²'20" W, González-Rocha et al. 13 (UAMIZ); en la comunidad de Huaxtla, junto a un riachuelo, $18^{\circ} 22^{\prime} 34.32^{\prime \prime}$ N, 99²'44.7" W, González-Rocha et al. 60 (UAMIZ); comunidad de Huaxtla, 18²2'39.1" N, 99²'45.7" W, González-Rocha et al. 61 (UAMIZ); en el poblado de Huaxtla, 18²2'43" N, 99²'46" W, Juárez et al. $38 a$ (HUMO); $1.5 \mathrm{~km}$ al NW de Xochipala, 18²5'50" N, 99³'19" W, Juárez et al. 168 a (HUMO); $1.5 \mathrm{~km}$ al W de Coaxitlán, 18²7'26.4" N, 99¹1'31.7" W, Juárez et al. 935, 936 (HUMO); 4 km al N de Huautla, 18²6'40" N, 98 59'4" W, Maldonado y Castro 158 (HUMO); sin localidad, Miranda 1478 (HUMO); $1.75 \mathrm{~km}$ al SE de Xochipala, 18 ${ }^{\circ} 24^{\prime} 15^{\prime \prime}$ N, 99 $2^{\prime} 17^{\prime \prime}$ W, Dante et al. 42 (HUMO); 1 km al NW de Huautla, 18 $26^{\prime} 44^{\prime \prime}$ N, 99 $2^{\circ} 7^{\prime \prime} \mathrm{W}$, Ramírez et al. 290 (HUMO); $1 \mathrm{~km}$ al W de Huaxtla, 18²2'54" N, 99³'13" W, Ramirez et al. 674 (HUMO); $1 \mathrm{~km}$ al NE de Rancho Viejo, 18²6'21" N, 990'18" W, Ramírez et al. 1522 (HUMO); Nexpa, Salazar 22 (HUMO); 2 km

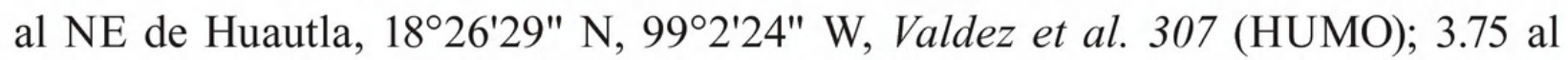
NW de Ajuchitlán, 18²7'55" N, 9859'1" W, Valdez et al. 564 (FCME, HUMO, MEXU); $0.5 \mathrm{~km}$ al SW de Ajuchitlán,18²7'59" N, 98 58'47" W, Valdez et al. 229 (HUMO); 3.75 km al NW de Ajuchitlán, 18²7'55" N, 9859'1" W, Valdez et al. 543 (HUMO); $1 \mathrm{~km}$ antes de la Mezquitera, por la camaronera, Vázquez 683 (MEXU); Valle de Vázquez - Los Hornos, cerca del camino antes de llegar al pueblo, Vázquez 2457 (MEXU); La Mezquitera, hondonada cerca del camino, Vázquez 2596 (MEXU); Huautla, Wilke 38 (MEXU). Xochitepec. $2 \mathrm{~km}$ al W de Xochitepec, atrás del Balneario Palo Bolero, carretera federal México - Acapulco, Donovan 9 (MEXU); carretera México - Acapulco, cerca de Palo Bolero km 93-94, Palacios 1150 (ENCB); Palo Bolero, cerca del camino entre la carretera federal a Acapulco y Las Huertas, Vázquez 1440, 1766, 1767 (MEXU). Yautepec. Paraje El Fortín, Barranca Honda, 1849'30" N, 996'13.3" W, Almonte et al. 227 (MEXU); $10 \mathrm{~km}$ al $\mathrm{S}$ Yautepec, por la carretera a Zacatepec, $500 \mathrm{~m}$ al N de la colonia Miguel Hidalgo, Chacón 117 (MEXU); Barranca Honda, Espejo 2530 (UAMIZ); Cañón de Lobos, Cuernavaca - Cuautla, F.G.M. 182 (MEXU); Barranca Honda, en la parte sur de la 
población, Gutiérrez 262 (MEXU); entre San Isidro y Barranca Honda, 1849'6.9" N, 996'4.2" W, Hernández 5 (HUMO); Cañón de Lobos, fondo de la barranca, km 20 carretera a Cuautla, Vázquez 243 (MEXU). Zacatepec. Sin localidad, 1 may 1967, Palacios s.n. (ENCB, MEXU).

Tabernaemontana tomentosa (Greenm.) A. O. Simões \& M. E. Endress, Taxon 59(3): 788. 2010. Stemmadenia tomentosa Greenm., Proc. Amer. Acad. Arts 35(16): 310. 1900. Tipo: México, Jalisco, Pringle 4370 (Holotipo: GH). Fig. 4E.

Stemmadenia palmeri Rose \& Standl., Contr. U.S. Natl. Herb. 23(4): 1156. 1924. Tipo: México, Sinaloa, Palmer 1470 (Holotipo: US).

Stemmadenia sinaloana Woodson, Ann. Missouri Bot. Gard. 15(4): 356, t. 48, f. 1. 1928. Tipo: México, Sinaloa, Lamb 467 (Holotipo: GH).

Stemmadenia decipiens Woodson, Ann. Missouri Bot. Gard. 15(4): 363. 1928. Tipo: México, Sinaloa, Rose 1614 (Holotipo: US).

Árboles o arbustos de 1-6 m de altura; tallos subcilíndricos, glabros. Hojas opuestas, láminas oblongo-elípticas a ligeramente obovadas, de 5-14 cm de largo $\times$ 3.5-7 cm de ancho, ápice acuminado, base cuneada, haz glabro, envés tomentoso en la intersección de la vena principal con las venas secundarias, con marcada venación secundaria en ambas superficies, peciolos de $5-15 \mathrm{~mm}$ de largo, generalmente glabros, a veces esparcidamente puberulentos. Inflorescencia una cima axilar de 1 a 4 flores, pedúnculo de $1-1.5 \mathrm{~cm}$ de largo, glabro a esparcidamente puberulento, pedicelo de 6-11 mm de largo, glabro; brácteas florales escariosas, ovadas, de 1-2.5 mm de largo $\times 1-2 \mathrm{~mm}$ de ancho, glabras; cáliz con 5 sépalos verdes, obovados, iguales, de $0.25-0.63 \mathrm{~cm}$ de largo $\times 2-3 \mathrm{~mm}$ de ancho, glabros a puberulentos, con hasta 15 coléteres dispuestos en 2 series, sépalos acompañados de 2 bracteolas verdes, ovadas, de 4-9 $\mathrm{mm}$ de largo $\times$ 3.5-7 $\mathrm{mm}$ de ancho, glabras; corola infundibuliforme, de color amarillo-crema, con crestas supra e infraestaminal, parte inferior del tubo de 1.3-1.9 $\mathrm{cm}$ de largo $\times$ 0.4-0.5 cm de diámetro, éste contorneado alrededor de los estambres, parte superior campanulada, de1.5-2 cm de largo, diámetro de la garganta de 1.5-1.8 $\mathrm{cm}$, los lóbulos oblicuamente obovados, de 2.5-3 cm de largo $\times 1.5-2.5 \mathrm{~cm}$ de ancho, redondeados, revolutos; estambres incluidos, filamentos libres, anteras de ca. $7 \mathrm{~mm}$ de largo libres de la cabeza estigmática; cabeza estigmática de ca. $1 \mathrm{~mm}$ de largo; ovario de ca. $2 \mathrm{~mm}$ de largo, rodeado de un nectario anular, de ca. $1 \mathrm{~mm}$ de largo. Folículos verde-grisáceos, reniformes o elipsoidales, ápice acuminado, con dos costillas laterales evidentes, de 3.5-4 cm de largo $\times$ 2-2.9 cm de diámetro, glabros; semillas numerosas, de ca. $1 \mathrm{~cm}$ de largo, con un arilo de color rojo o anaranjado. 
Especie endémica de México. Se conoce de Chihuahua, Colima, Guerrero, Jalisco, México, Michoacán, Morelos, Nayarit, Oaxaca, Sinaloa, Sonora y Veracruz (Juárez-Jaimes et al., 2007). En Morelos se ha colectado en Cuernavaca, Emiliano Zapata, Jiutepec, Puente de Ixtla, Tepoztlán, Tlaquiltenango y Yautepec. Fig. 5.

Esta planta crece en el bosque tropical caducifolio y en bosque de galería en altitudes de 1000 a $1900 \mathrm{~m}$. Se ha colectado en floración de abril a junio y en fructificación de julio a noviembre. Tabernaemontana tomentosa se distingue de $T$. odontadeniiflora por tener sépalos de igual longitud que llegan a medir hasta $6 \mathrm{~mm}$ de largo.

Ejemplares examinados. Cuernavaca. Campos de lava cerca de Cuernavaca, Pringle 6847 (MEXU); sin localidad, Rodríguez 73 (HUMO), Vázquez 1765 (MEXU). Emiliano Zapata. Tepetzingo, predio de la Cementera Moctezuma, 100 $\mathrm{m}$ debajo de donde inicia la banda de acarreo, Juárez et al. 706 (HUMO). Jiutepec. Lago Ahuayapan - Tejalpa, sin colector s.n. (UAMIZ); Cañón de Lobos y Pedregal de las Fuentes, Vázquez 1765 (MEXU); Pedregal de las Fuentes, terreno volcánico, Vázquez 704 (MEXU). Puente de Ixtla. 5 km camino al Zapote, en la intersección al poblado El Mango, 18²9'26" N, 99²0'38" W, González-Rocha et al. 10 (UAMIZ). Tepoztlán. Carretera Cuernavaca - Cuautla entre el km 15-16 al N de la carretera, en el Parque Nacional El Tepozteco, Flores-Castorena y Martínez (MORE); $5 \mathrm{~km}$ al S de Santa Catarina, El Texcal, 1855'33.6" N, 9908'21" W, González-Rocha et al. 215 (UAMIZ); $4.6 \mathrm{~km}$ al S de Santa Catarina, El Texcal, 1855'43.3" N, 9908'15.7" W, González-Rocha et al. 226 (UAMIZ), 227 (UAMIZ). Tlaquiltenango. Comunidad de Huaxtla, 18²2'39.1" N, 9902'45.7" W, González-Rocha et al. 62 (UAMIZ). Yautepec. Cañón de Lobos, 20 jun 1981, Contreras s.n. (MEXU); Amador Salazar; cañada de Lobos, Díaz 207 (ENCB, MEXU); 6 millas al E de Yautepec, Dixon 82 (MEXU); camino a la cañada Cañón de Lobos, El Progreso, Monte Negro, $50 \mathrm{~m}$ abajo del ojo de Agua El Altar, 1851'52.57" N, 998'8.34" W, González-Rocha et al. 73 (UAMIZ), Miguel-Vázquez et al. 40 (UAMIZ).

THENARDIA Kunth, Nov. Gen. Sp. (quarto ed.) 3: 209, t. 240. 1818[1819].

Lianas con látex transparente; tallos subcilíndricos, glabros o puberulentos, con coléteres interpeciolares diminutos e inconspicuos. Hojas opuestas, pecioladas, sin coléteres en la lámina, láminas pubescentes a glabras, membranáceas a papiráceas. Inflorescencia una cima subumbeliforme, axilar; brácteas florales no foliáceas; cáliz con sépalos iguales, foliáceos, glabros o puberulentos, con un coléter en la base de la cara adaxial; corola rotada, blanca, de color crema a vino, sin corona 
anular, sin lóbulos coronales libres, prefloración dextrocontorta, el tubo floral sin crestas supra o infraestaminales, recto; estambres exertos, filamentos enroscados en la base, anteras conniventes y aglutinadas a la cabeza estigmática, sin apéndices supra e infraestaminales; cabeza estigmática fusiforme con un anillo basal, no lobulada en la base; gineceo sincárpico, bicarpelar, ovario súpero, rodeado por 5 nectarios libres o ligeramente concrescentes. Frutos en folículos, sincárpicos, moniliformes unidos longitudinalmente, glabros; semillas comosas, planas.

Género con dos especies endémicas de México y otra conocida de México y Honduras. En Morelos se presenta la siguiente.

Thenardia floribunda Kunth, Nov. Gen. Sp. (quarto ed.) 3: 210-211, t. 240. 1818[1819]. Tipo: México, urbem Mexici. Humboldt \& Bonpland s.n. (Holotipo: P-HB). Fig. 4F.

Thenardia suaveolens M. Martens \& Galeotti, Bull. Acad. Roy. Sci. Bruxelles 11(6): 359-360. 1844. Tipo: México, Michoacán, Uruapan, Galeotti 1557 (Holotipo: BR). Thenardia tubulifera Woodson, Ann. Missouri Bot. Gard. 19(4): 381. 1932. Tipo: México, Jalisco, sin localidad precisa. Diguet s.n. (Holotipo: NY).

Nombre común: petatillo (Vázquez, 1974).

Lianas de hasta $7 \mathrm{~m}$ de altura; tallos subcilíndricos, glabros. Hojas opuestas, láminas elípticas, de 5-13 cm de largo $\times 1.5-5.5 \mathrm{~cm}$ de ancho, ápice largamente acuminado, base cuneada, haz glabro, envés esparcidamente puberulento y pubescente a lo largo de la vena media, sin marcada venación secundaria en ambas superficies, papiráceas, peciolos de $0.5-2 \mathrm{~cm}$ de largo, puberulentos. Inflorescencia una cima umbelliforme tricótoma, axilar, de 14 a 30 flores, pedúnculo primario de $2.5-10 \mathrm{~cm}$ de largo $\times$ de ca. $1 \mathrm{~mm}$ de diámetro, puberulento a glabro, pedúnculo secundario de 0.2-2.9 cm de largo, puberulento a glabro, pedicelo de 1.7-2.9 cm de largo, puberulento a glabro, brácteas secundarias verdes, de 1.2-2.2 $\mathrm{cm}$ de largo $\times 3-4 \mathrm{~mm}$ de ancho, glabras en ambas superficies, largamente elípticas; brácteas florales verdes, lanceoladas a filiformes, de 2-4.5 $\mathrm{mm}$ de largo $\times 0.5-1 \mathrm{~mm}$ de ancho, puberulentas; cáliz con 5 sépalos verdes, ovado-lanceolados, de 1-2 mm de largo, cortamente pilosos, con coléteres opuestos en cada sépalo; corola rotada de color magenta con blanco, lóbulos más o menos triangular-obovados, de 1.5-2.1 cm de largo $\times$ 0.9-1.2 $\mathrm{cm}$ de ancho, acuminados, extendidos; estambres exertos, filamentos enroscados en la base, de 6.6-8 $\mathrm{mm}$ de largo, aplanados, pilosos, anteras de 6.5-7 $\mathrm{mm}$ de largo, fusionadas a la cabeza estigmática; cabeza estigmática de ca. $1.5 \mathrm{~mm}$ de largo, estilo 
de 6.5-7 mm de largo; ovario de ca. $1.5 \mathrm{~mm}$ de largo, rodeado por 5 nectarios más pequeños que el ovario, de ca. $1 \mathrm{~mm}$ de largo. Folículos unidos longitudinalmente, de 12.5-15.6 cm de largo $\times 8-10 \mathrm{~mm}$ de diámetro; semillas 15 por folículo, de 12-19 $\mathrm{mm}$ de largo $\times 3 \mathrm{~mm}$ de ancho, coma blanquecino, de 3-3.5 $\mathrm{cm}$ de largo.

Planta endémica de México. Se conoce de Colima, Guerrero, Jalisco, México, Michoacán, Morelos, Nayarit y Oaxaca (Juárez-Jaimes et al., 2007). En Morelos está presente en los municipios de Tepoztlán, Tetela del Volcán, Tlayacapan y Zacualpan de Amilpas. Fig. 5.

Especie que se encuentra en las regiones húmedas al norte del estado en bosque de Quercus, en bosque tropical caducifolio y en zonas de transición de ambos tipos de vegetación, en altitudes de 1650 a 2020 m. Se colectó con flores en juliodiciembre y con frutos en diciembre y abril.

Ejemplares examinados. Tepoztlán. Tepozteco, al pie de la escalera terminal de hierro, Vázquez 451 (MEXU); Sierra de Tepoztlán ladera W, Vázquez 4987 (MEXU). Tetela del Volcán. 4 km al E de Tetela del Volcán, 4 ago 1963, Sánchez s.n. (ENCB), sin localidad, sin fecha de colecta, Lachica s.n. (ENCB). Tlayacapan. $1 \mathrm{~km}$ al SW de San José de Los Laureles, 18 58'26.5" N, 9900'09.1" W, González-Rocha et al. 24 (UAMIZ); ladera NE del cerro de Las Mariposas 1858'20.7" N, 9900'32.9" W, González-Rocha et al. 63 (UAMIZ); al N de la barranca Tepecapa, a $1.8 \mathrm{~km}$ al SW de San José de Los Laureles 1857'54" N, 9900'49.9" W, Hernández-Cárdenas et al. 334 (UAMIZ). Zacualpan de Amilpas. $2.89 \mathrm{~km}$ al E del poblado de Tlacotepec (en línea recta), 1804'59.9" N, 9846'41.8" W, González-Rocha et al. 286 (UAMIZ).

TONDUZIA Pittier, Contr. U.S. Natl. Herb. 12(2): 103. 1908.

Árboles o arbustos con látex blanco; tallos angulados a subcilíndricos, glabros o puberulentos, con coléteres inter e intrapeciolares, diminutos e inconspicuos. Hojas en verticilos de 3, raramente opuestas, pecioladas, sin coléteres en la lámina, láminas glabras, membranáceas. Inflorescencia corimbosa, axilar a subterminal; cáliz con sépalos iguales, foliáceos, glabros a puberulentos, sin coléteres en la cara adaxial; corola hipocrateriforme, blanca o de color crema, sin corona anular, sin lóbulos coronales libres, prefloración sinistrocontorta, tubo floral sin crestas supra o infraestaminales, recto; estambres incluidos, anteras no conniventes ni aglutinadas a la cabeza estigmática, sin apéndices supra e infraestaminales; cabeza estigmática fusiforme, no lobulada en la base; gineceo apocárpico, bicarpelar, ovario súpero, rodeado por un nectario anular. Frutos en folículos, apocárpicos, cilíndricos, subleñosos, glabros; semillas ciliadas en el margen, no comosas. 
Género neotropical con dos especies distribuidas desde México hasta Panamá. Para el país se conocen ambas, una de las cuales se ha registrado en Morelos.

Tonduzia longifolia (A. DC.) Markgr., Repert. Spec. Nov. Regni Veg. 20(561/576): 112. 1924. Rauvolfia longifolia A. DC., Prodr. 8: 338. 1844. Tipo: México, Oaxaca, Hartweg 491 (Holotipo: G-BOIS). Alstonia longifolia (A. DC.) Pichon, Bull. Mus. Natl. Hist. Nat., sér. 2, 19(3): 297. 1947. Fig. 4G.

Tonduzia macrantha Woodson, Ann. Missouri Bot. Gard. 24(1): 12. 1937. Tipo: Guatemala, Quetzaltenango, Skutch 871 (Holotipo: MO).

Árboles de 2-5 m de altura; tallos subcilíndricos, glabros, con coléteres inter e intrapeciolares de ca. $1 \mathrm{~mm}$ de largo. Hojas en verticilos, láminas angostamente elípticas, de 5-11 cm de largo $\times 1.5-3 \mathrm{~cm}$ de ancho, ápice acuminado, base agudo-cuneada, glabras en ambas superficies, membranáceas, con marcada venación secundaria en ambas superficies, peciolos de 4-10 $\mathrm{mm}$ de largo, glabros. Inflorescencia un corimbo axilar a subterminal de 9 a 16 flores, pedúnculo de 7-8 $\mathrm{mm}$ de largo, glabro, pedicelo de ca. $6 \mathrm{~mm}$ de largo, glabro; brácteas florales escariosas, lanceoladas, de ca. $1 \mathrm{~mm}$ de largo, glabras; cáliz con 5 sépalos verdes, ovados, de 0.9-1.3 mm de largo $\times$ 0.4-0.8 mm de ancho, glabros; corola hipocrateriforme, blanca, tubo de 4-6 $\mathrm{mm}$ de largo $\times$ 0.7-2 mm de diámetro, lóbulos elípticos, de 4.5-7.5 mm de largo $\times 1$ 1-3 $\mathrm{mm}$ de ancho, redondeados o agudos, recurvados; estambres incluidos, filamentos de ca. $0.5 \mathrm{~mm}$ de largo, anteras de 1-1.2 $\mathrm{mm}$ de largo, libres de la cabeza estigmática; cabeza estigmática de 0.6-1 mm de largo, estilo de 1.2-1.5 $\mathrm{mm}$ de largo, ovario de ca. 0.7-0.8 mm de largo, nectarios diminutos e inconspicuos. Folículos fusiformes, separados, subleñosos, de 6-7 $\mathrm{cm}$ de largo $\times$ 4-7 $\mathrm{mm}$ de diámetro, glabros; semillas pardas, elípticas, de 6-7 $\mathrm{mm}$ de largo $\times$ 2-3 $\mathrm{mm}$ ancho.

Especie distribuida desde México hasta Panamá. En México se conoce de Chiapas, Colima, Guerrero, Jalisco, Michoacán, Nayarit, Oaxaca, Puebla y Veracruz (Juárez-Jaimes et al., 2007). En Morelos se ha colectado en los municipios de Emiliano Zapata y Yautepec. Fig. 5.

Especie restringida al bosque tropical caducifolio de la Sierra de Montenegro en altitudes de 1300 a $1430 \mathrm{~m}$. La presencia de T. longifolia (A. DC.) Markgr. en el estado se conocía de un ejemplar de 1971 de Vázquez 3250 (MEXU); además, en las recientes exploraciones botánicas se colectó en dicha localidad y en el municipio de Emiliano Zapata, extendiendo su área de distribución conocida en la entidad. Florece y fructifica de junio a julio. El género Tonduzia fue considerado por Morales (1995) como parte de Alstonia R. Br.; sin embargo, Simões et al. (2007) demos- 
traron que Alstonia y Tonduzia son taxa diferentes. En la Flora Mesoamericana, Zarucchi (2009) reconoce a T. longifolia, en contraste con Morales $(1995,2009)$ y Juárez-Jaimes et al. (2007) que aceptan dos especies (T. longifolia y T. stenophylla) para México y Centroamérica. Ambos taxa se diferencian por la longitud del tubo y por el tamaño de los lóbulos de la corola (Morales 1995, 2009); no obstante, los especímenes examinados en este estudio muestran que los caracteres utilizados por Morales $(1995,2009)$ se superponen en el mismo individuo, creando ambigüedad en su delimitación.

Ejemplares examinados. Emiliano Zapata. $2 \mathrm{~km}$ después de Temimilcingo

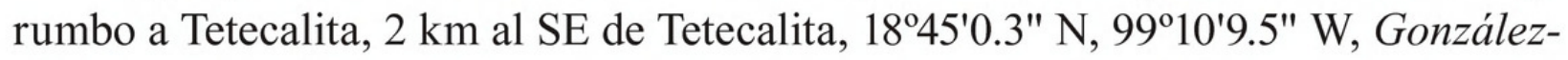
Rocha et al. 170 (UAMIZ). Yautepec. Camino a la cañada Cañón de Lobos, El Progreso, Sierra de Monte Negro, 1851'52.59" N, 9907'51.47" W, González-Rocha et al. 74, 75, 77 (UAMIZ); Cañón de Lobos, ladera bajando desde La Pedrera, Vázquez 3250 (MEXU).

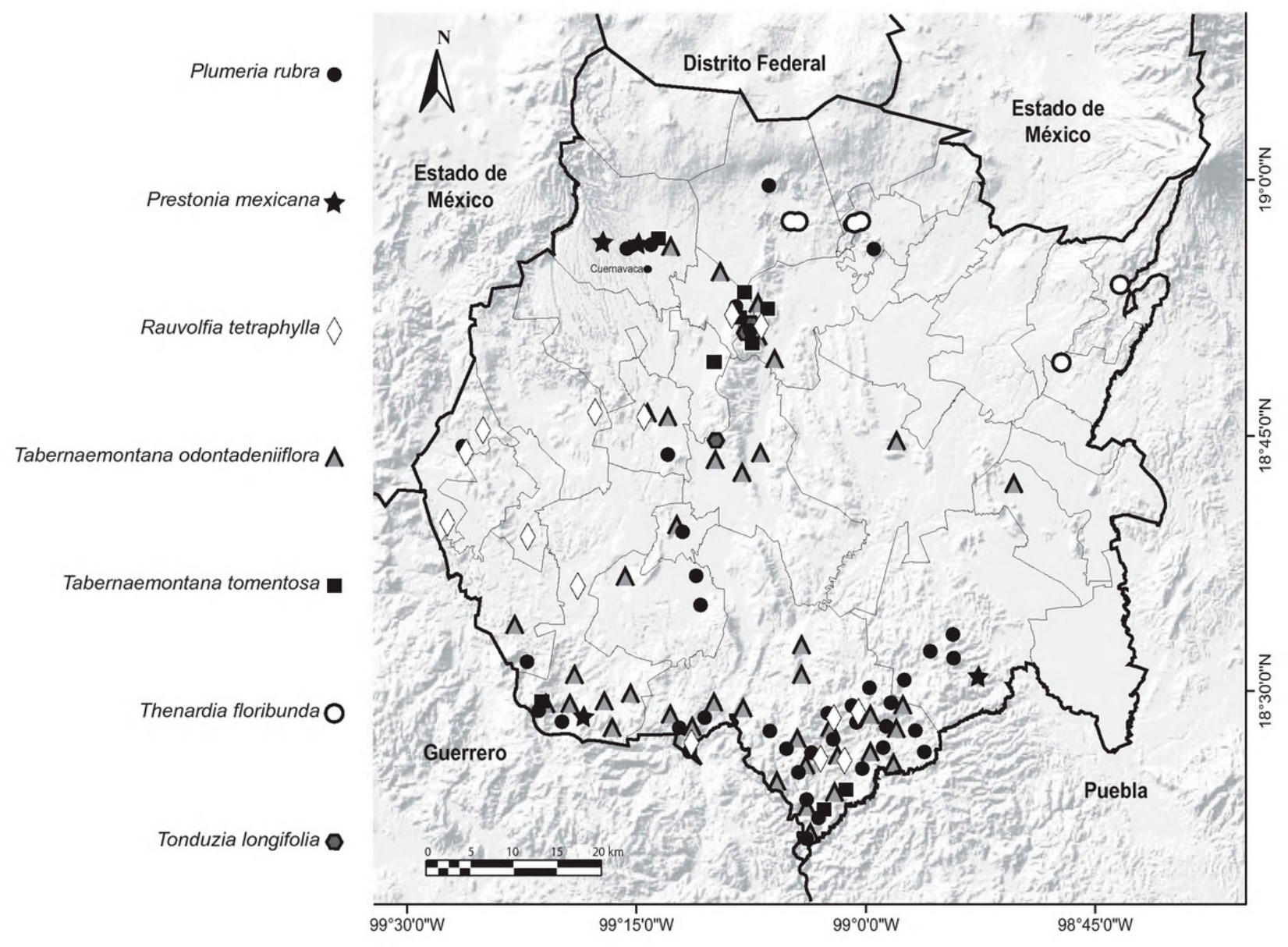

Fig. 5. Distribución de las especies de Plumeria, Prestonia, Rauvolfia, Tabernaemontana, Thenardia y Tonduzia en el estado de Morelos. 


\section{DISCUSIÓN}

Con base en la revisión de material herborizado y de recolectas en el área de estudio se reportan diez géneros y 14 especies (Cuadro 1). La subfamilia Rauvolfioideae es la mejor representada con seis géneros y ocho especies, mientras que Apocynoideae tiene cuatro y seis, respectivamente. Los géneros con mayor número de componentes son Mandevilla (3), Cascabela (2) y Tabernaemontana (2) y representan 50\% de la diversidad registrada, a su vez Haplophyton, Laubertia, Plumeria, Prestonia, Rauvolfia, Thenardia y Tonduzia no albergan más que una sola.

El mayor número de especies se encuentra en bosque tropical caducifolio (13), seguido por el de Quercus (3), el de galería (3) y en menor cantidad el de coníferas (1) (Cuadro 1). Mandevilla holosericea crece únicamente en bosques húmedos de coníferas y Quercus de los municipios de Cuernavaca, Tepoztlán y Tlayacapan. A su vez, Cascabela y Rauvolfia están asociados al tropical caducifolio, al de galería y además pueden prosperar en vegetación secundaria y en algunas zonas urbanas. Ocho especies crecen únicamente en bosque tropical caducifolio: Laubertia contorta, M. subsagittata, Prestonia mexicana, Haplophyton cimicidum, Plumeria rubra, Tabernaemontana odontadeniiflora, T. tomentosa y Tonduzia longifolia.

En el estado se distribuyen seis especies endémicas de México: Cascabela thevetioides, Laubertia contorta, Mandevilla foliosa, M. holosericea, Tabernaemontana tomentosa y Thenardia floribunda (Cuadro 1).

En este estudio se excluyeron los nombres de Mandevilla hypoleuca (Benth.) Pichon, citada en Bonilla-Barbosa y Villaseñor, (2003) y Vallesia glabra (Cav.) Link mencionada por Juárez-Jaimes et al. (2007), debido a que no se encontraron ejemplares en los herbarios antes mencionados, en bases de datos virtuales y tampoco fueron recolectadas a causa de la falta de precisión en los datos correspondientes a sus localidades. Alvarado-Cárdenas y Morales (2014) en la revisión de Mandevilla para México no reportan a M. hypoleuca para Morelos. Por otro lado en este trabajo no se incluyeron especies introducidas (16 taxa), entre las que destacan Cascabela peruviana (Pers.) Raf.; Catharanthus roseus (L.) G. Don y Vinca major L., con alto valor estético y comercial en la entidad.

En cuanto a la distribución, la mayoría de los registros se concentran en la parte norte y sur del estado, donde se localizan el Corredor Biológico Chichinautzin y la Reserva de la Biósfera Sierra de Huautla. Esta tendencia de ubicación coincide con lo indicado en los trabajos de Galván (2009) y Miguel-Vázquez (2010). De los 33 municipios que conforman el estado, los que albergan más de 50\% del total géneros estudiados son Coatlán del Río, Cuernavaca, Jiutepec, Puente de 
Cuadro 1. Especies de las subfamilias Apocynoideae y Rauvolfioideae en el estado de Morelos y tipos de vegetación donde habitan. (*) Especies endémicas de México. BC: bosque de coníferas, BQ: bosque de Quercus, BTC: bosque tropical caducifolio y BG: bosque de galería.

\begin{tabular}{|c|c|c|}
\hline Subfamilia & Taxa & $\begin{array}{l}\text { Tipos de } \\
\text { Vegetación }\end{array}$ \\
\hline \multirow[t]{6}{*}{ Apocynoideae } & 1. Laubertia contorta (M. Martens \& Galeotti) Woodson* & BTC \\
\hline & 2. Mandevilla foliosa (Müll. Arg.) Hemsl. * & BTC, BQ \\
\hline & 3. M. holosericea (Sessé \& Moc.) J. K. Williams * & $\mathrm{BC}, \mathrm{BQ}$ \\
\hline & 4. M. subsagittata (Ruiz et Pav.) Woodson & BTC \\
\hline & 5. Prestonia mexicana A. DC. & BTC \\
\hline & 6. Thenardia floribunda Kunth* & BTC,BQ \\
\hline \multirow[t]{8}{*}{ Rauvolfioideae } & 7. Cascabela ovata Cav. & BTC, BG \\
\hline & 8. C. thevetioides (Kunth) Lippold* & BTC, BG \\
\hline & 9. Haplophyton cimicidum A. DC. & BTC \\
\hline & 10. Plumeria rubra L. & BTC \\
\hline & 11. Rauvolfia tetraphylla $\mathrm{L}$. & BTC, BG \\
\hline & $\begin{array}{l}\text { 12. Tabernaemontana odontadeniiflora A. O. Simões \& } \\
\text { M. E. Endress }\end{array}$ & BTC \\
\hline & $\begin{array}{l}\text { 13. T. tomentosa (Greenm.) A. O. Simões \& M. E. } \\
\text { Endress* }\end{array}$ & BTC \\
\hline & 14. Tonduzia longifolia (A. DC.) Markgr. & BTC \\
\hline
\end{tabular}

Ixtla, Tepoztlán, Tlaquiltenango, Xochitepec y Yautepec. No se reportan registros de los de Atlatlahucan, Axochiapan, Huitzilac, Ocuituco, Temoac y Totolapan. En los municipios restantes varía entre uno y tres géneros. Finalmente, este estudio define algunos avances sobre el conocimiento de la Flora de Morelos y reconoce la necesidad de ampliar la exploración de los representantes de esta familia en algunas áreas del estado.

\section{AGRADECIMIENTOS}

Expresamos nuestra gratitud a los encargados de los herbarios ENCB, FCME, HUMO, MEXU, MORE y UAMIZ por todas las facilidades otorgadas en la revisión del material botánico. Damos gracias a Francisco Morales, especialista en las apo- 
cináceas tropicales por sus valiosos comentarios y por permitir el uso del material fotográfico de Mandevilla subsagittata. También agradecemos el apoyo en el trabajo de campo a los Bióls. Alejandro Flores Morales, Luis Gil Galván González, Rodrigo A. Hernández Cárdenas y Mónica I. Miguel Vázquez. Los resultados de este artículo forman parte de la tesis de licenciatura de la primera autora que contó con el apoyo del Programa de Mejoramiento del Profesorado-Universidad Autónoma del Estado de Morelos y de los Programas Integrales de Fortalecimiento InstitucionalUniversidad Autónoma del Estado de Morelos.

\section{LITERATURA CITADA}

Alvarado-Cárdenas, L. O. 2003. La familia Apocynaceae en el Valle de Tehuacán-Cuicatlán (Puebla-Oaxaca). Tesis de licenciatura. Facultad de Ciencias, Universidad Nacional Autónoma de México. México, D.F., México. 122 pp.

Alvarado-Cárdenas, L. O. 2004a. Apocináceas. In: García, J. A., M. J. Ordoñez y M. Briones (eds.). Biodiversidad de Oaxaca. Instituto de Biología, Universidad Nacional Autónoma del Estado de México-Fondo Oaxaqueño para la Conservación de la Naturaleza y World Wildlife Foundation. México, D.F., México. pp. 171-176.

Alvarado-Cárdenas, L. O. 2004b. Apocynaceae. Flora del Valle de Tehuacán-Cuicatlán 38: $1-57$.

Alvarado-Cárdenas, L. O. 2007. Stemmadenia oaxacana Alvarado-Cárdenas (Apocynaceae), una nueva especie para el estado de Oaxaca, México. Candollea 62: 189-192.

Alvarado-Cárdenas, L. O. y H. Ochoterena. 2007. A phylogenetic analysis of the CascabelaThevetia species complex (Plumerieae, Apocynaceae) based on morphology. Ann. Missouri Bot. Gard. 94: 298-323.

Alvarado-Cárdenas, L. O. y J. F. Morales. 2014. El género Mandevilla (Apocynaceae: Apocynoideae, Mesechiteae) en México. Bot. Sci. 92(1): 59-79.

Anónimo. 1981. Síntesis geográfica de Morelos. Coordinación General de los Servicios Nacionales de Estadística, Geografía e Informática, Secretaría de Programación y Presupuesto. México, D.F., México. 110 pp.

Anónimo. 1994. Inventario nacional forestal periódico. Memoria nacional. Subsecretaría Forestal y de Fauna Silvestre, Secretaría de Agricultura y Recursos Hidráulicos (SARH). México, D.F., México. 81 pp.

Anónimo. 1988. Decreto por el que se declara el área de protección de la Flora y la Fauna silvestre, ubicada en los municipios de Huitzilac, Cuernavaca, Tepoztlán, Jiutepec, Tlalnepantla, Yautepec, Tlayacapan y Totolapan, Morelos. Órgano del Gobierno Constitucional de los Estados Unidos Mexicanos, Diario Oficial de la Federación. 30.XI.1988.

Anónimo. 1999. Superficie de la República Mexicana por estados. Instituto Nacional de Estadística Geografía e Informática-Dirección General de Geografía (INEGI-DGG). Disponible: http://www.inegi.gob.mx. Consultado en enero de 2010. 
Anónimo. 2000. Marco geoestadístico. Instituto Nacional de Estadística Geografía e Informática. Disponible: http://www.inegi.gob.mx consultado en enero de 2010.

Anónimo. 2012. Mapa del estado de Morelos y la República Mexicana. Laboratorio Interdisciplinario de Sistemas de Información Geográfica (LISIG), Universidad Autónoma del Estado de Morelos. Cuernavaca, Morelos, México.

Bonilla-Barbosa, J. R. y J. L. R. Villaseñor. 2003. Apocynaceae. In: Catálogo de la flora del estado de Morelos. Centro de Investigaciones Biológicas, Universidad Autónoma del Estado de Morelos. Cuernavaca, Morelos, México. pp. 51-52.

Calderón de Rzedowski G. y J. Rzedowski. 1998. Apocynaceae. Flora del Bajío y de Regiones Adyacentes 70: 1-64.

Cerros-Tlatilpa, R y M. A. Espejo-Serna. 1998. Contribución al estudio florístico de los cerros el Sombrerito y las Mariposas (Zoapapalotl) en el municipio de Tlayacapan, Morelos, México. Polibotánica 8: 29-46.

Chimal, A. y V. Corona. 2003. Arbustos mexicanos con potencial ornamental. In: Mejía Muñoz, J. M y A. Espinosa Flores (comp.). Plantas nativas de México con potencial ornamental. Análisis y perspectivas. Universidad Autónoma Chapingo. Chapingo, México. 217 pp.

Contreras-MacBeath, T., J. C. D. Boyás, T. J. I. Martínez, M. S. Taboada, M. O. M. Pohle, A. P. Herrera, F. P. Saldaña y G. R. Oliver. 2004. Marco de referencia físico. In: Contreras-MacBeath, T., M. F. Jaramillo y D. J. C. Boyás (eds.). La diversidad biológica en Morelos: Estudio del estado. Comisión Nacional para el Conocimiento y Uso de la Biodiversidad y Universidad Autónoma del Estado de Morelos. Cuernavaca, Morelos, México. 155 pp.

Diego-Pérez, N. 2004. Apocynaceae. Flora de Guerrero 20: 1-118.

Dorado, O., B. Maldonado, D. M. Arias, V. Sorani, R. Ramírez, E. Leyva y D. Valenzuela. 2005. Programa de conservación y manejo Reserva de la Biosfera Sierra de Huautla. Comisión Nacional de Áreas Naturales Protegidas (CONANP)-Secretaría de Medio Ambiente y Recursos Naturales (SEMARNAT). México, D.F., México. $143 \mathrm{pp}$.

Endress, M. E. 2004. Apocynaceae: Brown and now. Telopea 10: 525-541.

Endress, M. E. y P. V. Bruyns. 2000. A revised classification of the Apocynaceae $s$. $l$. Bot. Rev. (Lancaster) 66: 1-56.

Endress, M. E., S. S. Liede y U. Meve. 2007. Advances in Apocynaceae: The enlightenment, an introduction. Ann. Missouri Bot. Gard. 94: 259-267.

Flores, C. Á. 1988. Los árboles ornamentales de la ciudad de Cuernavaca, Morelos. Tesis de licenciatura. Escuela de Ciencias Biológicas, Universidad Autónoma del Estado de Morelos. Cuernavaca, Morelos, México. 205 pp.

Flores-Castorena, Á. y D. Martínez-Alvarado. 2010. Capítulo 5: Sinopsis florística. In: Bonilla-Barbosa, J. R., V. M. Mora, J. Luna-Figueroa, H. Colín y S. Santillán-Alarcón (eds.). Biodiversidad, conservación y manejo en el Corredor Biológico Chichinautzin, Condiciones actuales y perspectivas. Universidad Autónoma del Estado de Morelos. Cuernavaca, Morelos, México. pp. 69-97.

Galindo, B. G. y R. Fernández. 2002. Inventario florístico del municipio de Amacuzac, Morelos, México. Polibotánica 13: 107-135. 
Galván, L. 2009. Las plantas parásitas del estado de Morelos. Tesis de licenciatura. Facultad de Ciencias Biológicas, Universidad Autónoma del Estado de Morelos. Cuernavaca, Morelos, México. 130 pp.

Hernández-Cárdenas, R. A. 2012. Las plantas vasculares de la barranca Tepecapa en el municipio de Tlayacapan, Morelos, México. Tesis de licenciatura. Facultad de Ciencias Biológicas, Universidad Autónoma del Estado de Morelos. Cuernavaca, Morelos, México. 37 pp.

Juárez-Jaimes, V., L. O Alvarado-Cárdenas y J. L. Villaseñor. 2007. La familia Apocynaceae sensu lato en México: diversidad y distribución. Rev. Mex. Biodivers. 78: 459-482.

Koch, I. 2002. Estudos das espécies neotropicais do gênero Rauvolfia L. (Apocynaceae). Tesis de doctorado. Universidade Estadual de Campinas. Campinas, São Paulo, Brasil. 292 pp.

Laudadio, C. y M. Davis. 2003. Cardiac glycosides for treating muscle pain and spasm. United States Patent Application Publication. US 20030229029 AI, Pensylvania, USA.

Leeuwenberg, A. J. M. 1994. A revision of Tabernaemontana. Two. The New World species and Stemmadenia. Royal Botanic Gardens. Kew, UK. 254 pp.

Martínez, M. 1991. Catálogo de nombres vulgares y científicos de plantas mexicanas. Fondo de Cultura Económica. México, D.F., México. 1247 pp.

McLaughlin, J. L., B. Freedman, R. G. Powel y C. R. Jr. Smith. 1980. Insecticidal and cytotoxic agents of Thevetia. J. Econ. Entomol. 73: 398-402.

Miguel-Vázquez, M. I. 2010. La familia Onagraceae en el estado de Morelos. Tesis de licenciatura. Facultad de Ciencias Biológicas, Universidad Autónoma del Estado de Morelos. Cuernavaca, Morelos, México. 133 pp.

Morales, J. F. 1995. Evaluación del género Alstonia (Apocynaceae) en Centroamérica. Phytologia 78: 192-194.

Morales, J. F. 1996. Novelties in Prestonia (Apocynaceae). Novon 6: 285-287.

Morales, J. F. 1997. A synopsis of the genus Prestonia (Apocynaceae) section Tomentosae in Mesoamerica. Novon 7: 59-66.

Morales, J. F. 1998. A synopsis of the genus Mandevilla (Apocynaceae) in Mexico and Central America. Brittonia 50: 214-233.

Morales, J. F. 2002. Studies in neotropical Apocynaceae 1: A revision of the genus Laubertia. Rhodora 104: 170-185.

Morales, J. F. 2009. La familia Apocynaceae (Apocynoideae, Rauvolfioideae) en Guatemala. Darwiniana 47: 140-184.

Morales, J. F. y M. Méndez. 2005. Estudios en las Apocynaceae neotropicales XXII: Nuevos realineamientos taxonómicos en el género Stemmadenia (Apocynaceae, Rauvolfioideae, Tabernaemontaneae. Candollea 60: 345-371.

Rao, A. S. 1956. A revision of Rauvolfia, with particular reference to the American species. Ann. Missouri Bot. Gard. 43: 253-354.

Rzedowski, J. 1978. Vegetación de México. Limusa. México, D.F., México. 432 pp.

Simões, A. O., T. Livshultz, E. Conti y M. E. Endress. 2007. Phylogeny and systematics of the Rauvolfioideae (Apocynaceae) based on molecular and morphological evidence. Ann. Missouri Bot. Gard. 94: 268-297. 
Simões, A. O., M. E. Endress y E. Conti. 2010. Systematics and character evolution of Tabernaemontaneae (Apocynaceae, Rauvolfioideae) based on molecular and morphological evidence. Taxon 59: 772-790.

Snyder, H. R., H. F. Strohmayer y R. A. Mooney. 1958. The insecticidal principles of Haplophyton cimicidum. The nature of the acidic function of haplophytine. J. Am. Chem. Soc. 80 (14): 3708-3710.

Soria, R. G. 1985. Flora de Morelos. Descripción de especies vegetales de la selva baja caducifolia del Cañón de Lobos, Mpio. de Yautepec. Programa florístico-ecológicoCoordinación de Investigación, Universidad Autónoma del Estado de Morelos. Cuernavaca, Morelos, México. pp. 15-21.

Standley, P. C. 1924. Apocynaceae. In: Trees and shrubs of Mexico. Contr. U.S. Natl. Herb. 23: $1116-1147$.

Standley, P. C. y L. O. Williams. 1966. Apocynaceae. Flora of Guatemala. Fieldiana Bot. 24(8): 334-407.

Vázquez, S. J. 1974. Catálogo de las plantas contenidas en el "Herbario L'Amagatall". Ciencia 29: 1-138.

Williams, J. K. 1995. Miscellaneous notes on Haplophyton (Apocynaceae: Plumerieae: Haplophytinae). Sida 16: 469-475.

Williams, J. K. 1996.The Mexican genera of the Apocynaceae (sensu A. DC), with key and additional taxonomic notes. Sida 17: 197-213.

Williams, J. K. 1998a. A new combination in Mexican Mandevilla (Apocynaceae). Sida 18: 237-239.

Williams, J. K. 1998b. A revision of Thenardia (Apocynaceae, Apocynoideae). Lundellia 1: 78-94.

Williams, J. K. 2009. Haplophyton A. DC. In: Davidse, G., M. Sousa-Sánchez, S. Knapp y C. F. Chiang (eds.). Flora Mesoamericana 4: Cucurbitaceae a Polemoniaceae. Universidad Nacional Autónoma de México. México, D.F., México. pp. 676-677.

Woodson, R. E. 1928. Studies in the Apocynaceae II. A revision of the genus Stemmadenia. Ann. Missouri Bot. Gard. 15: 34 1-379.

Woodson, R. E. 1933. Studies in the Apocynaceae IV. The American genera of Echitoideae. Ann. Missouri Bot. Gard. 20: 605-790.

Woodson, R. E. 1936a. Thenardia. Studies in the Apocynaceae IV. Ann. Missouri Bot. Gard. 23: 271-276.

Woodson, R. E. 1936b. Prestonia. Studies in the Apocynaceae IV. Ann. Missouri Bot. Gard. 23: 276-367.

Woodson, R. E. 1938a. An evaluation of the genera Plumeria L. and Himatanthus Willd. Ann. Missouri Bot. Gard. 25: 189-224.

Woodson, R. E. 1938b. Apocynaceae. N. Amer. Fl. 29: 103-192.

Zarucchi, J. L. 2009. Alstonia. In: Davidse, G., M. Sousa-Sánchez, S. Knapp y C. F. Chiang (eds.). Flora Mesoamericana 4: Cucurbitaceae a Polemoniaceae. Universidad Nacional Autónoma de México. México, D.F., México. pp. 667. 